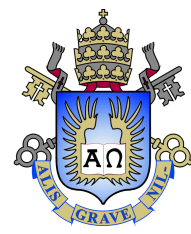

Cristiana Duarte Rangel de Abreu

\title{
Análise do deslocamento de bolhas de gás em fluido viscoplástico
}

Dissertação apresentada como requisito parcial para obtenção do grau de Mestre pelo Programa de Pós-graduação em Engenharia Mecânica do Departamento de Engenharia Mecânica do Centro Técnico Científico da PUC-Rio.

Orientadora: Profa. Mônica Feijó Naccache 


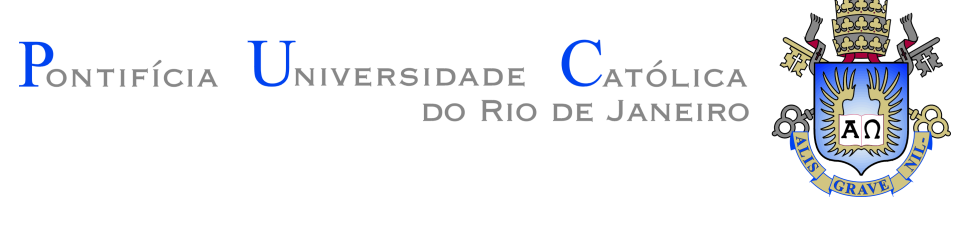

Cristiana Duarte Rangel de Abreu

\section{Análise do deslocamento de bolhas de gás em fluido viscoplástico}

Dissertação apresentada como requisito parcial para obtenção do grau de Mestre pelo Programa de Pós-graduação em Engenharia Mecânica do Departamento de Engenharia Mecânica do Centro Técnico Científico da PUC-Rio. Aprovada pela Comissão Examinadora abaixo assinada.

Profa. Mônica Feijó Naccache Orientadora

Departamento de Engenharia Mecânica - PUC-Rio

Prof. Paulo Roberto de Souza Mendes Departamento de Engenharia Mecânica - PUC-Rio

Dr. Flávio Henrique Marchesini de Oliveira

Halliburton

Prof. Márcio da Silveira Carvalho Coordenador Setorial do Centro Técnico Científico - PUC-Rio

Rio de Janeiro, 28 de Setembro de 2016 
Todos os direitos reservados. É proibida a reprodução total ou parcial do trabalho sem autorização da universidade, do autor e da orientadora.

\section{Cristiana Duarte Rangel de Abreu}

Graduou-se em Engenharia Química na Universidade do Estado do Rio de Janeiro - UERJ (2011). Pós-graduada em Engenharia de Petróleo na PUC-Rio (2012). Trabalhou como engenheira de vendas de equipamentos na Superquip Serviços e Equipamentos (2009-2011). Atua como consultora de perfuração na Landmark/Halliburton desde 2012.

Ficha Catalográfica

Abreu, Cristiana Duarte Rangel de

Análise do deslocamento de bolhas de gás em fluido viscoplástico / Cristiana Duarte Rangel de Abreu; orientadora: Mônica Feijó Naccache. - 2016.

$66 \mathrm{f} . ; 30 \mathrm{~cm}$

Dissertação (mestrado) - Pontifícia Universidade Católica do Rio de Janeiro, Departamento de Engenharia Mecânica, 2016.

Inclui bibliografia

1. Engenharia Mecânica - Teses. 2. Bolhas de gás. 3. Fluido viscoplástico. 4. Escoamento multifásico. 5. Herschel-Bulkley. I. Naccache, Mônica Feijó. II. Pontifícia Universidade Católica do Rio de Janeiro. Departamento de Engenharia Mecânica. III. Título. 


\section{Agradecimentos}

Primeiramente agradecer a Deus por tornar esta oportunidade possível, diante de todas as dificuldades.

À minha orientadora Mônica Feijó Naccache por toda a dedicação e auxílio para a realização deste trabalho.

À Halliburton por permitir a minha liberação durante o horário de trabalho para cursar as matérias do Mestrado.

Ao CNPq e à PUC-Rio, pelos auxílios concedidos, sem os quais este trabalho não poderia ter sido realizado.

Aos amigos que fiz na PUC-Rio, em especial a Martha Salles, Thiago Pinheiro, Gabriel Serrão e Leonardo Soares, por toda a ajuda quando precisei e por terem tornado o curso mais leve.

Aos professores do Departamento de Engenharia Mecânica da Pontifícia Universidade Católica do Rio de Janeiro, pelos conhecimentos adquiridos ao longo desses dois anos.

Ao Matheus Vieira por toda a paciência na reta final do Mestrado e por toda a ajuda na realização deste trabalho.

Aos meus pais que sempre se dedicaram a minha formação intelectual e moral e que são a base de todas as minhas conquistas acadêmicas e profissionais e que, assim como minha irmã e meus amigos mais próximos, sempre acreditaram no meu potencial e me incentivaram.

A todos aqueles que contribuíram, direta ou indiretamente, para esta formação que se torna mais uma vitória em minha vida, meus sinceros agradecimentos. 


\section{Resumo}

Abreu, Cristiana Duarte Rangel de; Naccache, Mônica Feijó. Análise do deslocamento de bolhas de gás em fluido viscoplástico. Rio de Janeiro, 2016. 66p. Dissertação de Mestrado - Departamento de Engenharia Mecânica, Pontifícia Universidade Católica do Rio de Janeiro.

O escoamento de bolhas de gás em fluidos não-newtonianos é muito importante em diversas aplicações, tais como biorreatores, processamento de alimentos e operações de perfuração e cimentação de poços de petróleo, contudo poucos estudos abordam este tema. No presente trabalho é analisado o escoamento ascendente de bolhas de gás em fluido viscoplástico, modelado aqui como fluido Herschel-Bulkley. Utilizou-se uma abordagem bidimensional, aproximada por placas paralela. O escoamento multifásico foi numericamente simulado fazendo uso do método de volumes finitos VOF (volume of fluid), o qual resolve as equações de conservação de massa e momento aclopado a uma equação para a fração volumétrica dos fluidos. A influência de fatores tais como tensão limite de escoamento, dimensão da bolha, número de bolhas e distância entre as bolhas escoando em um fluido viscoplástico foram investigadas. Os resultados indicaram que a tensão limite de escoamento tem grande impacto na velocidade de deslocamento da bolha. No caso de mais de uma bolha escoando foi também observado que o deslocamento de uma bolha altera a velocidade de ascenção das outras, fazendo com que elas se unam, e a medida em que a distância entre as bolhas aumenta a interferência é eliminada e as mesmas escoam como bolhas individuais. Além disso, foi verificado que, dependendo do tamanho da bolha escoando, a parede interfere na sua velocidade de ascenção. Por fim foi analisada a mudança no formato da bolha, podendo-se observar que em número de Reynolds menores a mesma apresenta um formato esférico e a medida em que este parâmetro aumenta, a bolha vai se deformando e adquire uma forma elipsoidal. Os resultados qualitativos do presente estudo numérico foram comparados com alguns trabalhos experimentais encontrados na literatura e corresponderam relativamente bem.

\section{Palavras-chave}

Bolhas de gás; Fluido viscoplástico; Escoamento multifásico; Herschel-Bulkley. 


\section{Abstract}

Abreu, Cristiana Duarte Rangel de; Naccache, Mônica Feijó (Advisor). Analysis of gas bubble flow through a viscoplastic fluid.. Rio de Janeiro, 2016. 66p. MSc. Dissertation - Departamento de Engenharia Mecânica, Pontifícia Universidade Católica do Rio de Janeiro.

The gas bubble displacement in non-Newtonian fluids is important in many applications, including bioreactors, food processing and drilling and cementing of oil wells however a few studies have investigated this issue. The motion of gas bubbles in a viscoplastic fluid, modeled as a Herschel-Bulkley fluid, is analysed in the present work. A bidimensional approach was used, approximated by parallel plates. The multiphase flow was numerically simulated using the finite volume technique VOF (volume of fluid), which solves the conservation equations of mass and momentum coupled to an equation for the volume fraction of the fluids. Is was investigated the influence of factors such as fluid yield stress, bubble size, number of bubbles rising in the viscoplastic fluid and also the distance between them. The results indicated that the yield stress has great impact on the bubble rising velocity. In the case of multiple bubbles flowing it was also observed that the displacement of one bubble influences the rising velocity of the others, causing them to join together. As the distance between the bubbles increase the interference is eliminated and the bubbles flow separately. Furthermore, it was found that there was an wall interference depending on the size of the bubble. Lastly, it was analysed the change in the shape of the bubble. It could be observed that for lower Reynolds number the bubbles presented an spherical shape and as this parameter increases it turns into an elipsoidal shape. The qualitative results of the present study agreed relatively well with experimental works found in the literature.

\section{Keywords}

Gas bubble; Viscoplastic fluid; Multiphase flow; Herschel-Bulkley. 


\section{Sumário}

1 Introdução 12

1.1 Introdução 12

1.2 Motivação 13

$\begin{array}{lll}1.3 & \text { Objetivo } & 14\end{array}$

2 Revisão Bibliográfica $\quad 15$

3 Modelagem matemática $\quad \mathbf{2 0}$

3.1 Formulação do problema 20

$\begin{array}{ll}3.2 & \text { Reologia do fluido em estudo } \\ 3.2 .1\end{array}$

3.2.1 Modelo de Bingham 21

3.2.2 Modelo de Herschel-Bulckley 22

3.3 Equações governantes 22

3.4 Equações adimensionais 24

3.5 Raio mínimo para escoamento da bolha 26

$\begin{array}{ll}\text { 3.6 Cálculo do coeficiente de arraste } & 27\end{array}$

3.7 Cálculo do raio equivalente em domínio tridimensional 27

4 Modelagem numérica $\quad 29$

4.1 Fluidodinâmica computacional 29

4.2 Método dos volumes finitos $\quad 29$

4.2.1 Discretização temporal 31

4.2.2 Discretização espacial $\quad 32$

4.2.3 Método de cálculo dos gradientes 32

4.2.4 Esquema para equação de pressão 33

4.2.5 Esquema de discretização da equação do momento 34

4.2.6 Esquema de discretização da fração volumétrica 34

4.3 Acoplamento Velocidade-Pressão $\quad 35$

4.4 Método VOF $\quad 35$

4.5 Fatores de sub-relaxação 36

4.6 Modelo Herschel-Bulkley regularizado 36

$\begin{array}{lll}4.7 & \text { Teste de malha } & 37\end{array}$

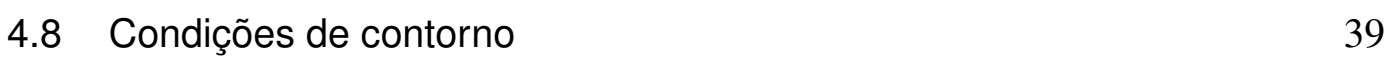

4.8.1 Condição pressure outlet 40

4.8.2 Condição wall 40

5 Resultados $\quad 41$

5.1 Análise do escomento de uma bolha 41

5.1.1 Influência da dimensão da bolha nos resultados 41

5.1.2 Influência da parade nos resultados 43

5.1.3 Análise do formato da bolha 46

5.1.4 Influência da tensão limite de escoamento nos resultados 47

5.1.5 Análise do coeficiente de arraste 48

5.2 Análise do escomento com mais de uma bolha na vertical 50 
5.3 Análise do escomento com mais de uma bolha na horizontal 57

5.4 Validação do modelo bidimensional $\quad 59$

6 Conclusão e recomendações $\quad 61$

6.1 Conclusões 61

6.2 Sugestões para trabalhos futuros 62

7 Referências bibliográficas $\quad 64$ 


\section{Lista de figuras}

3.1 Esquemático do domínio computacional 20

3.2 Comportamento reológico de fluido viscoplástico 21

3.3 Forças atuantes na bolha de gás 26

4.1 Volume de controle exemplificado para ilustrar a discretização de uma equação de transporte escalar 30

4.2 Variação no centróide das células $c_{0}$ e $c_{i}$ na direção do vetor $r_{i} \quad 33$

4.3 Fatores de sub-relaxação utilizados para pressão, densidade, forças de corpo, equação de momento e pressão. 36

$\begin{array}{lll}\text { 4.4 Malha estruturada } & 37\end{array}$

4.5 Efeito da malha na velocidade de ascenção da bolha 38

4.6 Malha estruturada em geometria 3D 38

$\begin{array}{lll}4.7 & \text { Condições de contorno do problema } & 39\end{array}$

5.1 Relação entre a velocidade média da bolha e seu raio máximo 42

5.2 Comparativo entre simulações com anular de 0,033 m e 0,066 m 44

5.3 Campo taxa de deformação para bolhas escoando em anular de $0,033 \mathrm{~m}$

5.4 Campo velocidade para bolhas escoando em anular de 0,033 m 45

5.5 Campos taxa de deformação para $\tau_{0}=2$ e $\tau_{0}=4$ considerando raio da bolha igual a $0,0065 \mathrm{~m}$

5.6 Relação entre o número de Reynolds generalizado e a dimensão da bolha

5.7 Evolução do formato da bolha para diferentes número de Reynolds 47

5.8 Número de Reynolds generalizado versus $Y \quad 48$

$5.9 \mathrm{C}_{d}$ versus $\mathrm{Re}_{g}$

5.10 Gráfico Re vs x/H para escoamento de 2 bolhas com espaçamento de $0,01 \mathrm{~m}$ e $\tau_{0}=2$

5.11 Gráfico Re vs $\mathrm{x} / \mathrm{H}$ para escoamento de 2 bolhas com espaçamento de $0,02 \mathrm{~m}$ e $\tau_{0}=2$

5.12 Gráfico Re vs $\mathrm{x} / \mathrm{H}$ para escoamento de 2 bolhas com espaçamento de $0,03 \mathrm{~m}$ e $\tau_{0}=2$

5.13 Campos (a) velocidade e (b) taxa de deformação em diferentes instantes de tempo para o caso $\mathrm{C}$

5.14 Gráfico Re vs x/H para escoamento de 2 bolhas com espaçamento de $0,04 \mathrm{~m}$ e $\tau_{0}=2$

5.15 Gráfico Re vs x/H para escoamento de 1 bolha com raio de 0,002 $\mathrm{m}$ e $\tau_{0}=2$

5.16 Gráfico Re vs x/H para escoamento de 2 bolhas com espaçamento de $0,02 \mathrm{~m}$ e $\tau_{0}=4$

5.17 Gráfico Re vs x/H para escoamento de 3 bolhas com espaçamento de $0,02 \mathrm{~m}$ e $\tau_{0}=2$

5.18 Campo de velocidade em diferentes instantes do escoamento do caso $\mathrm{E}$ 
5.19 Campo taxa de deformação em diferentes instantes do escoamento do caso $\mathrm{E}$

5.20 Trajetória de par de bolhas escoando paralelamente com diferentes distâncias iniciais entre elas: (a) $3 \mathrm{~mm}$ (b) $7 \mathrm{~mm}$ (c) 11 $\mathrm{mm}$ 


\section{Lista de tabelas}

5.1 Relação de simulações realizadas variando-se o raio da bolha para diferentes valores de tensão limite de escoamento

5.2 Raio crítico para $\tau_{0}$ igual a 2 e $4 \mathrm{~Pa}$

43

5.3 Simulações realizadas com mais de uma bolha

50

5.4 Simulações realizadas com mais de uma bolha escoando na horizontal 


\section{Introdução}

\section{1}

\section{Introdução}

Os escoamentos multifásicos podem ser encontrado em diversas áreas da engenharia, podendo o escoamento de bolhas de gás em fluidos viscoplásticos ser visto em diferentes aplicações tais como processamento de alimentos, extração de óleo, processamento de resíduos, reatores bioquímicos, cimentação de poços de petróleo, dentre outros. Em muitas delas, a análise detalhada do comportamento das bolhas ao escoar no fluido é essencial para o desempenho e/ou segurança do projeto e por este motivo tem estimulado muitas pesquisas. Na maioria das vezes, escoamentos multifásicos são muito complexos devido a presença de mais de uma fase no escoamento, exigindo um número adicional de equações para fechamento de modelos matemáticos que expressam o fenômeno físico. Dificulta também o fato de o mesmo depender de diversos parâmetros reológicos, podendo a fase contínua ser um fluido newtoniano ou não newtoniano e a fase dispersa ser gasosa, sólida ou líquida, sendo também possível sofrer a influência de parâmetros cinemáticos e da geometria do espaço onde ocorre o escoamento.

O presente trabalho analisa o deslocamento de bolhas de gás através de um fluido viscoplástico. Pela natureza do fluido, a complexidade é maior do que o escoamento de bolhas em fluidos Newtonianos, para o qual podem ser encontrados diversos estudos na literatura. Diferentemente do Newtoniano, o fluido viscoplástico apresenta variação de viscosidade cinemática com a taxa de cisalhamento nele aplicada, após a superação de uma tensão crítica. Esta classe de materiais é caracterizada por esta tensão crítica, chamada tensão limite de escoamento $\left(\delta_{0}\right)$, que deve ser excedida para que o fluido se deforme ou escoe. Abaixo desta tensão o material se comporta como um sólido, e não se deforma. Uma vez que a tensão aplicada exceda esta tensão limite, a curva de escoamento, que fornece a relação entre tensão e taxa de deformação, pode ser linear ou não linear. Deve ser notado que este tipo de material não é exatamente um fluido, de acordo com a definição rigorosa da física. Pode-se explicar este tipo de comportamento postulando que o material, quando em repouso, consiste em uma estrutura tri-dimensional de rigidez ou força suficiente para resistir qualquer tensão externa inferior ao $\tau_{0}$. Para tensão superiores ao $\tau_{0}$, a 
estrutura se quebra e o material passa a se comportar como um fluido.

Como resultado deste comportamento dos fluidos viscoplásticos, enquanto uma bolha de gás sempre irá ascender, devido a flutuabilidade, em fluidos com tensão limite de escoamento igual a zero, ela pode permanecer estacionária em fluido viscoplástico se a força de empuxo for insuficiente para vencer a força viscosa devido a tensão limite de escoamento. Similarmente, uma esfera sólida não irá cair através de um fluido viscoplástico a menos que a força gravitacional líquida seja grande o suficiente para ultrapassar a tensão limite de escoamento. Um objeto em movimento através de um fluido viscoplástico estará rodeado por uma região deste material que se estende a uma certa distância, porém longe deste objeto, onde a tensão local não mais excede a tensão limite de escoamento, o material irá se comportar como um sólido.

\section{2 \\ Motivação}

O entendimento do comportamento físico de sistemas multifásicos é de vital importância na otimização dos processos, segurança e no projeto de equipamentos que estejam envolvidos. Como por exemplo, o escoamento de bolhas de gás durante a cimentação de poços de petróleo. Seu conhecimento é muito importante para garantir a segurança do poço, das pessoas que trabalham ao redor e do meio ambiente.

A invasão de fluido da formação no espaço durante a etapa de perfuração ou cimentação de um poço, mais comumente chamado de kick, é um problema de grande relevância na indústria do petróleo. O tipo de fluido invasor mais perigoso é o gás, sendo leve, ele pode subir e alcançar o contato com a superfície mais facilmente. Caso haja falha na detecção ou controle deste influxo e ele migre até a superfície, resultará em um blowout, causando um fluxo descontrolado de fluidos que podem levar a resultados catastróficos e a perda do poço.

As consequências de um blowout podem ser muito trágicas, tanto para as pessoas que estão operando no poço quanto para a vida marinha e ao meio ambiente, uma vez que nessa situação ocorrem vazamentos de fluido para o meio ambiente que podem provocar explosões, incêndios e um acidente de grandes proporções.

Em virtude da possibilidade de acidentes gravíssimos, se torna importante o estudo do escoamento de bolhas de gás tanto durante a perfuração quanto na cimentação de poços de petróleo para avaliação do comportamento destas ao migrarem pelo anular. 


\section{Objetivo}

Visto a importância do estudo do comportamento do escoamento de bolhas de gás durante a cimentação, este trabalho objetiva verificar a influência de alguns fatores neste tipo de escoamento em um fluido viscoplástico, sendo eles:

1. Tensão limite de escoamento;

2. Dimensão da bolha;

3. Número de bolhas escoando e distância entre elas. Cabe ressaltar que tanto as pastas de cimento como os fluidos de perfuração tem comportamento viscoplástico.

4. Ao final foi analisado e comparado, através de simulações numéricas utilizando o método VOF (volume of fluid), o escoamento de bolhas de ar em um fluido viscoplástico em geometria 2D e 3D afim de validar o domínio bidimensional utilizado.

Vale destacar que o resultado do presente estudo não se limita apenas ao deslocamento de bolhas de gás em pastas de cimento uma vez que este tipo de escoamento multifásico, como mencionado anteriormente, pode ser encontrado em diversas outras indústrias. 


\section{2 \\ Revisão Bibliográfica}

Existe na literatura uma vasta gama de trabalhos envolvendo o escoamento de bolhas de gas em fluidos newtonianos como por exemplo o caso do trabalho numérico e experimental realizado por Magnaudet et al. (2000) que analisa as forças hidrodinâmicas atuando em bolhas isoladas se deslocando em fluidos não viscosos. O trabalho realizado por Kulkarni et al. (2005) apresentou uma revisão bastante abrangente do comportamento de bolhas em um sistema gás-líquido. Também pode ser citado o livro de Clift et al. (1978) o qual aborda muito bem os princípios fundamentais e equações governantes do comportamento de bolhas escoando em fluidos newtonianos. Este se tornou referência em trabalhos posteriores. Porém pode ser observado que o comportamento deste escoamento em fluidos viscoplásticos não tem sido muito explorado, deste modo, o presente trabalho visa complementar os poucos estudos realizados neste campo.

Nesta seção serão apresentados os principais aspectos de interesse dos estudos revisados que serviram como referência para o trabalho em questão.

Sabe-se que a movimentação de bolhas em fluidos viscoplásticos só irá ocorrer quando a força devida ao empuxo for suficiente para superar a força devida a tensão limite de escoamento do fluido. Alguns autores definiram um parâmetro adimensional, chamado de yield parameter $\left(\mathrm{Y}_{g}\right)$, para analisar qualitativamente os resultados da física envolvida no escoamento. Este parâmetro é dado pela razão entre a tensão limite de escoamento e a tensão devido ao empuxo, a partir da qual a bolha não irá se movimentar no fluido. De acordo com Sirkorski et al. (2009), este parâmetro é definido pela equação a seguir:

$$
Y=\frac{2 \pi \tau_{0} R_{\max }^{2}}{\rho g V_{b}}
$$

Onde $R_{\max }$ é o raio máximo da bolha, $g$ é a aceleração da gravidade, $\rho$ é a massa específica do fluido (que possui um valor muito mais alto do que a massa específica do ar na bolha), $V_{b}$ é o volume da bolha e $\tau_{0} R$ a tensão limite de escoamento.

Em seu trabalho experimental, o autor mencionado acima fez uso deste parâmetro para analisar a dependência do número de Reynolds sobre o mesmo, verificando através de um gráfico Re versus $\mathrm{Y}$, qual o valor de Y crítico acima do qual não se observa mais movimentação da bolha. Esta mesma definição do 
parâmetro Y também pode ser encontrada no trabalho realizado por Beris et al (1985), utilizando o raio máximo da bolha no cálculo da força devido ao limite de escoamento no numerador, porém se diferencia um pouco da definição usada por Dubash e Frigaard (2004 e 2007) e também por Tsamopoulos et al. (2008). Estes autores se basearam em um raio efetivo, definido por $\mathrm{R}_{\text {eff }}$ utilizado no numerador e também se diferenciou por um fator numérico adicional de 1,5. A diferença entre as definições é muito pequena e os resultados encontrados foram qualitativamente os mesmos, independente da equação utilizada.

Segundo Sirkorski et al. (2009), a definição de Y reflete melhor a física envolvida: a força de arraste irá depender da real área de secção transversal da bolha enquanto a força de empuxo será proporcional ao volume da bolha. Segundo o autor, uma vez que a tensão limite de escoamento afeta o formato da bolha, a utilização de um raio efetivo na definição de Y poderia não capturar toda a dependência da tensão limite de escoamento presente no problema.

Nesta área de estudo de escoamento de bolhas de gás em fluidos viscoplásticos podem ser encontrados alguns experimentos realizados para avaliar o comportamento e formato de bolhas em Carbopol. Este é um fluido muito utilizado em experimentos por ser límpido e possuir um comportamento muito próximo ao de um fluido viscoplástico ideal, se comportando muito pouco como elástico a baixas taxas de cisalhamento. Os autores Sirkorski et al. (2009) avaliaram o escoamento e formato de bolhas em dispersão de Carbopol com valores de tensão limite de escoamento igual a 24 e $34 \mathrm{~Pa}$ em um sistema onde os efeitos da parede são muito pequenos. Eles verificaram em seus experimentos um aumento aproximadamente linear da velocidade de ascensão da bolha com o raio da bolha, acima de um valor de raio crítico. Foi também observado um valor de Y crítico por volta de 0,5 , acima do qual a força de empuxo não é suficiente para vencer a tensão limite de escoamento. Valor este que correspondeu qualitativamente as previsões teóricas. Em relação ao formato da bolha, foi observado uma cabeça arredondada e uma cauda mais afunilada. Este mesmo formato também foi observado nos experimentos realizados por Dubash et al. (2004 e 2007), segundo eles, o mesmo é uma característica geral de bolhas em dispersão de Carbopol. Todas as bolhas em seus experimentos possuem este formato de gota invertida e os mesmos acreditam que a elasticidade do fluido resulta em uma esteira negativa atrás da bolha que estica a extremidade traseira da mesma resultando em uma cauda afunilada. Este formato de bolha também foi observado nos experimentos realizados por Mougin et al. (2012). Porém ao verificar outros estudos de escoamento de bolhas de gás em fluido viscoplásticos, como os realizados por Dimakopoulos et al. (2013) e Tsamopoulos et al. (2008), pode-se notar que, em nenhum destes dois, o formato da bolha próximo às condições críticas reproduziram o formato de gota invertida encontrado nos estudos mencionados 
anteriormente, o que levanta dúvidas se isto se deve a elasticidade, tixotropia ou efeitos da parede.

Dimakopoulos et al. (2013) tentaram reproduzir numericamente o formato observado no estudo de Dubash et al. (2004 e 2007) porém as iterações nunca convergiram para tais formatos. Deste modo os mesmos atribuíram este formato aos seguintes motivos: (1) As soluções de Carbopol possuem baixa elasticidade o que pode ser significativo na cauda da bolha onde um escoamento mais lento ocorre e próximo ao eixo de simetria o escoamento é elongacional. Sabe-se que as bolhas assumem um formato de gota invertida em fluidos viscoelástico. (2) Outra razão pode se dar ao fato de o Carbopol ser tixotrópico, que pode levar a um fenômeno que não pode ser previsto em modelos viscoplásticos.

Pode-se notar que os principais estudos mencionados anteriormente ainda não produziram resultados consistentes para explicar os diferentes formatos de bolhas observados. Uma maneira de explicar se baseia na diferença no confinamento do fluido e no nível de tensão limite de escoamento. Assim como a elasticidade, a tensão interna também parece afetar o formato da bolha. Tsamopoulos et al. (2008) sugeriram uma lista de motivos que acreditam poder explicar estas diferenças:

1. A elasticidade não ter sido levada em consideração;

2. Possível tixotropia do material;

3. Proximidade das paredes, o que poderia impor um formato de gota devido ao fluxo reverso. Este formato seria mantido pela presença da tensão limite de escoamento.

O presente estudo poderá servir para complementar estas teorias a respeito dos diferentes formatos das bolhas escoando em fluido viscoplástico.

O presente estudo também analisou o comportamento do escoamento de duas bolhas de gás na horizontal em fluido viscoplástico, assim como no trabalho realizado por Islam et al (2015). Observa-se na literatura que poucos experimentos foram realizados com bolhas colocadas lado a lado horizontalmente em fluidos nãonewtonianos. No referente estudo, o escoamento e interação entre um par de bolhas em um fluido não-newtoniano (solução de goma xantana) foi simulado numericamente, utilizando o método VOF, onde um modelo de tensão superficial contínuo e o modelo Power Law foram adotados para representar a tensão superficial e as propriedades reológicas do fluido não-newtoniano, respectivamente. O software de fluidodinâmica computacional utilizado para resolver as equações governantes foi o Fluent, assim como no presente estudo, empregando o pressure based solver.

No estudo mencionado acima foram realizadas 17 simulações a fim de avaliar os efeitos da distância horizontal inicial entre o par de bolhas, do alinhamento 
angular oblíquo entre elas e as propriedades reológicas do fluido não newtoniano onde elas escoavam.

Em relação ao efeito da diferença na distância horizontal inicial entre o par de bolhas, foi observado através dos resultados um efeito repulsivo maior para par de bolhas com a distância entre elas menor e também pode-se observar que a maior variação na trajetória de escoamento das bolhas ocorreu em distâncias menores, devido ao forte efeito repulsivo como resultado de um grande volume de vórtices gerado entre as bolhas. Foi também analisada a diferença no formato das bolhas ao variar as distâncias iniciais entre elas e observou-se que para distâncias maiores o formato variou mais do que para distâncias maiores. Isto se deve ao forte campo de vórtices situado entre as duas bolhas que mantem a interação entre elas e também a força de interação na direção horizontal, que varia com o tempo. Este fator também contribui para que a velocidade de ascenção das bolhas com distância inicial entre elas menor seja inferior a observada para par de bolhas com distância inicial maior, que sobem com maior rapidez.

Por outro lado, considerando o alinhamento oblíquo, uma força repulsiva maior entre as bolhas foi vista quando o ângulo foi reduzido. Porém, coalescência oblíqua ocorreu devido a alta atração entre as bolhas em ângulos maiores, o que independe do índice de comportamento do fluido (n). Também foi percebido que o efeito repulsivo assim como a variação do formato da bolha de esférico para irregular são mais significativos em índices de comportamento do fluido menores $(\mathrm{n}<0,5)$ devido ao efeito pseudoplástico e concluído que o campo de fluxo ao redor das bolhas sofre mudanças significativas com a variação deste índice, o que pode levar a diferenças notáveis na velocidade de ascenção da bolha.

No presente estudo foram feitas também simulações considerando o escoamento de mais de uma bolha na vertical, o que também pode ser encontrado no estudo feito por Piau et al. (2012). Porém neste trabalho, as bolhas foram injetadas no fluido em momentos diferentes, só 30 dias após a primeira bolha ter sido injetada é que a segunda bolha foi injetada e então foram analisados seu formato e comportamento. Foi observado que a primeira bolha sofre uma expansão quase isotrópica durante a injeção e essa expansão tende a ser perturbada pelas tensões internas no fluido quando a bolha atinge o equilíbrio entre tensão superficial e tensão limite de escoamento do fluido, por um lado e força de empuxo do outro. As bolhas seguintes foram canalizadas diretamente pelo caminho preferencial, no momento em que foram injetadas. Em relação ao formato, foi observado que durante a injeção, o formato mudou de quase esférico para uma forma mais tubular. Este formato é acompanhado pelo aumento na velocidade de ascenção. A partir disto, foi concluído que a primeira bolha claramente modificou as condições de contorno do caminho preferencial uma vez que a segunda bolha tem uma velocidade de ascensão 
diferente assim como formato, porém seguindo a mesma trajetória da primeira.

Os resultados encontrados nas referências mencionadas acima foram muito importantes para auxiliar no entendimento do comportamento observado nas simulações realizadas no presente trabalho bem como justificativa para os mesmos. 


\section{3 \\ Modelagem matemática}

\section{1}

\section{Formulação do problema}

No presente trabalho foi considerado o fluxo de bolhas de ar, de volume $V_{b}$, em movimento ascendente em um fluido viscoplástico, representado pelo modelo Herschel-Bulkley. A fim de representar o escoamento num anular de poço utilizouse como primeira aproximação a geometria de placas paralelas, desprezando assim a curvatura dos dutos. Dessa forma, foi considerando inicialmente um domínio computacional bidimensional (posteriormente foi feita uma comparação com o resultado em domínio tridimensional), com as seguintes dimensões: 0,033m de largura e 0,5m de altura. Estas dimensões foram escolhidas para representar uma geometria real de um espaço anular entre a parede de um poço de petróleo de 12 1/4 polegadas $(0,311 \mathrm{~m})$ de diâmetro e um revestimento de $95 / 8$ polegadas $(0,244 \mathrm{~m})$ de diâmetro.

No estágio inicial da simulação a bolha de ar é inserida no centro do domínio, na direção y, e o seu centro a $0,01 \mathrm{~m}$ do fundo do domínio na direção $\mathrm{x}$, como esquematizado na Figura 3.1.

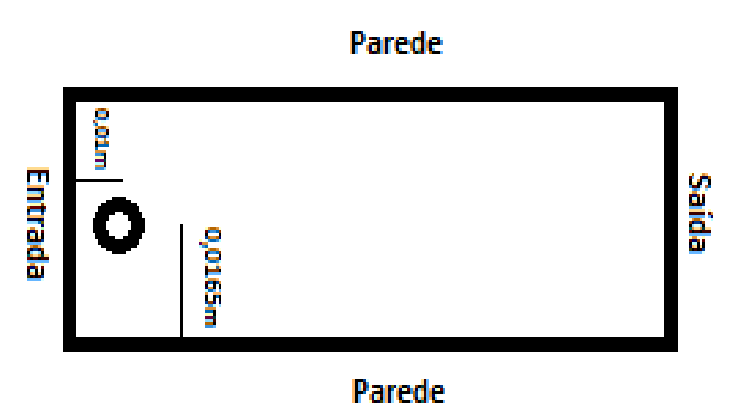

Figura 3.1: Esquemático do domínio computacional

Foi também considerado regime laminar e fluido incompressível. $\mathrm{O}$ ar foi modelado como gás perfeito. 


\section{2 \\ Reologia do fluido em estudo}

Segundo Bird et al. (2004), fluidos viscoplásticos são definidos, de acordo com seu comportamento reológico, como um material de características sólidas se a tensão exercida sobre ele for menor que a tensão de limite de escoamento. Contudo, se essa tensão for maior que esse limite, esse material passa ter um comportamento líquido e tem a capacidade de escoar, com uma grande queda em sua viscosidade. O limite de escoamento é justamente o ponto onde, se a tensão exercida for aumentada, o material passa a ter comportamento líquido, caso contrário, tem comportamento sólido. Na Figura 3.2 é apresentado um gráfico que reproduz estas características dos fluidos viscoplásticos. Nele são plotadas as curvas de dois dos modelos mais amplamente utilizados para representar o comportamento de fluidos viscoplásticos: Bingham e Herschel-Bulkley.

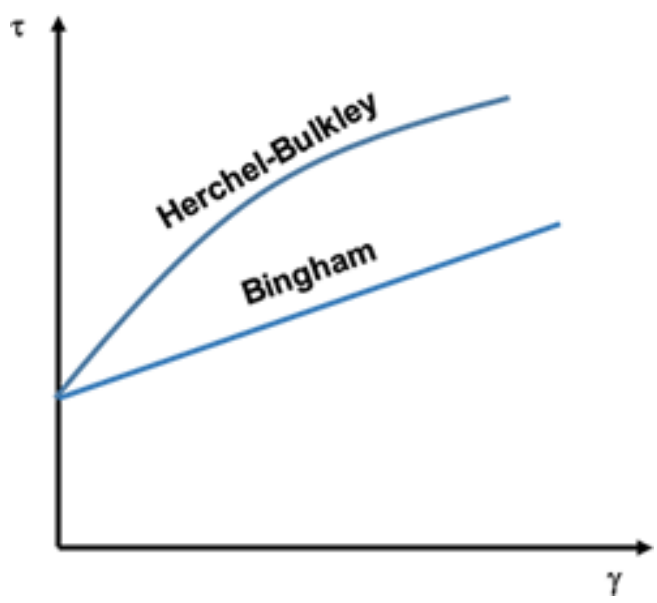

Figura 3.2: Comportamento reológico de fluido viscoplástico

A seguir são apresentadas as definições destes dois modelos reológicos, tendo sido o modelo Herschel-Bulkley escolhido para representar o fluido do presente trabalho, que em geral é caracterizado pela existência de uma região sólida e uma região que exibe uma viscosidade plástica dependente da taxa de cisalhamento.

\subsection{1}

\section{Modelo de Bingham}

O modelo de Bingham é o mais simples e talvez o mais utilizado para descrever o comportamento de fluidos do tipo viscoplástico. Os materiais que são caracterizados por este modelo, quando submetidos a baixas tensões não escoam, a não ser que a tensão aplicada ultrapasse uma tensão limite. Este comportamento é representado pelas seguintes equações:

$$
\tau=\tau_{0}+\mu_{\infty p} \dot{\gamma} \quad \text { quando } \quad \tau \geq \tau_{0}
$$




$$
\dot{\gamma}=0 \quad \text { quando } \quad \tau<\tau_{0}
$$

Onde $\tau_{0}$ é a tensão limite de escoamento, e $\mu_{p}$ a viscosidade plástica. A função viscosidade aparente acima da tensão limite de escoamento é dada na equação (3-3):

$$
\eta=\mu_{\infty}+\frac{\tau_{0}}{\dot{\gamma}}
$$

Abaixo da tensão limite de escoamento, a viscosidade tende a infinito.

\subsection{2}

\section{Modelo de Herschel-Bulckley}

Este modelo é uma generalização do modelo simples de Bingham, com a viscosidade plástica dependente da taxa de cisalhamento, com um comportamento de lei de potencia. É então um modelo de três parâmetros, que pode ser representado pela seguinte equação:

$$
\eta=\left\{\begin{array}{lr}
\frac{\tau_{0}}{\dot{\gamma}}+k \dot{\gamma}^{n-1} & \text { quando } \tau \geq \tau_{0} \\
\infty & \text { quando } \tau<\tau_{0}
\end{array}\right.
$$

Conforme a equação acima, o modelo recai no modelo de fluido Power-Law quando $\tau_{0}=0$. Além disso, se $n=1$ obtêm-se o modelo de Bingham, e se $n=1$ e $\tau_{0}=0$ o fluido modelado é Newtoniano.

\section{3}

\section{Equações governantes}

Para tratar o problema de escoamento multifásico foi utilizado o método VOF (volume of fluid), por este motivo as equação apresentadas a seguir contem a fração volumétrica. Este método resolve um conjunto de equações de conservação de massa e obtem a fração volumétrica de cada fase $\alpha_{i}$ através do domínio. A soma das frações deve ser igual a 1 em cada volume de controle. Deste modo, se $\alpha_{i}=0$, a célula não contem a fase $i$, se $\alpha_{i}=1$, a célula está completa com a fase $i$ e caso $0<\alpha_{i}<1$, a célula contem a interface entre os fluidos.

As equações que governam o problema são as equações de conservação de massa e momento:

$$
\begin{gathered}
\frac{\partial \rho(\alpha)}{\partial \mathrm{t}}+\nabla \cdot \rho(\alpha) \vec{u}=0 \\
\rho(\alpha)\left(\frac{\partial \vec{u}}{\partial t}+\nabla \vec{u} \cdot \vec{u}\right)=-\nabla P+\rho(\alpha) \vec{g}+\nabla \cdot[2 \mu(\alpha) \vec{D}]+\vec{F}_{s}
\end{gathered}
$$

Onde $\rho$ é a massa específica do fluido, $\vec{u}$ é o vetor velocidade do fluido, $P$ é a pressão, $\vec{F}_{s}$ é a força de corpo além da gravitacional e $\mu$ é o coeficiente de viscosidade dinâmica. O tensor taxa de deformação $\vec{D}$ é descrito como segue: 


$$
\vec{D}=\frac{1}{2}\left(\nabla \vec{u}+\vec{u}^{T}\right)
$$

A massa específica $\rho(\alpha)$ e o coeficiente de viscosidade cinemática $\mu(\alpha)$ médios locais são avaliados pela distribuição local da função fração volumétrica $\alpha$ :

$$
\begin{aligned}
& \rho(\alpha)=\rho_{l}\left(\alpha_{1}\right)+\rho_{g}\left[1-\alpha_{1}\right] \\
& \mu(\alpha)=\mu_{l}\left(\alpha_{1}\right)+\mu_{g}\left[1-\alpha_{1}\right]
\end{aligned}
$$

Onde $\rho_{l}$ e $\rho_{g}$ são as massas específicas do líquido e do gás e $\mu_{l}$ e $\mu_{g}$ as viscosidades do líquido e do gás, respectivamente. A fração volumétrica $(\alpha)$ é definida como a fração do líquido dentro de um volume de controle ou célula, onde $\alpha$ é igual a 0 para a célula somente cheia de gás e 1 para célula cheia de líquido e valores entre 0 e 1 para interfaces de líquido e gás na célula. A interface entre as fases é obtida pela solução da equação da continuidade para $\alpha_{i}$ para uma das fases:

$$
\frac{\partial \alpha_{i}}{\partial t}+\nabla \cdot\left(\vec{V} \alpha_{i}\right)=0
$$

A fração volumétrica da outra fase é obtida através da equação de restrição: $\alpha_{1}+\alpha_{2}=1$.

Neste tipo de escoamento que está sendo analisado o efeito da força devido à tensão interfacial é significativo, deste modo a simulação deste escoamento multifásico será o mais fiel a realidade se melhor for avaliada a curvatura da interface entre o gás e o líquido. Quando o método VOF é empregado para rastrear a posição da interface, o tratamento dos efeitos da tensão interfacial se torna uma tarefa complexa, tendo em vista que os mesmos só podem ser considerados numa região muito estreita, que corresponde à interface.

A fim de melhor tratar este problema, Brackbill et al. (1992) desenvolveram um método numérico, chamado continuum surface force (CSF), usado para calcular a movimentação da interface gás-líquido, que é incorporado na equação do movimento (3-6) sob a forma de uma força de corpo $\left(\vec{F}_{s}\right)$, que atua numa região limitada em torno da interface.

Esta força de corpo é calculada através da seguinte equação:

$$
\vec{F}_{s}=\sigma \frac{\rho k \nabla F_{l}}{0,5\left(\rho_{l}+\rho_{g}\right)}
$$

Onde $F_{l}$ é a fração da fase líquida, $\sigma$ é o coeficiente de tensão interfacial e $k$ é a curvatura da interface, que é definida em termos do divergente do vetor unitário normal à interface $(\hat{n})$, calculado conforme segue:

$$
k=-(\nabla \cdot \hat{n})=\frac{1}{|\vec{n}|}\left[\left(\frac{\vec{n}}{|\vec{n}|} \cdot \nabla\right)|\vec{n}|-(\nabla \cdot \vec{n})\right] ; \text { onde } \hat{n}=\frac{\vec{n}}{|\vec{n}|}
$$




\section{4}

\section{Equações adimensionais}

A adimensionalização das equações é feita com o objetivo de obter os parâmetros envolvidos no problema e possibilita a identificação de novas relações e padrões que sem este processo poderiam não ser identificados.

As equações adimensionais utilizadas neste estudo foram obtidas fazendo uso das variáveis adimensionais que são definidas a partir de valores característicos, sendo os mesmo apresentados a seguir.

Velocidade característica

$$
u_{c}=\sqrt{g D}
$$

Tensão característica

$$
\tau_{c}=\eta_{c} \dot{\gamma}_{c}
$$

Comprimento característico

$$
L_{c}=D
$$

Taxa de cisalhamento característica

Viscosidade característica

$$
\dot{\gamma}_{c}=\frac{u_{c}}{L_{c}}
$$

$$
\eta_{c}=\eta\left(\dot{\gamma}_{c}\right)
$$

Comprimento adimensional

$$
x^{*}=\frac{x}{D} ; y^{*}=\frac{y}{D}
$$

Viscosidade adimensional

Velocidade adimensional

$$
\eta^{*}=\frac{\eta}{\eta_{c}}
$$

$$
u^{*}=\frac{u}{\sqrt{g D}}
$$

Tensão cisalhante adimensional

Tempo adimensional

$$
\tau_{0}^{*}=\frac{\tau_{0}}{\tau_{c}}
$$

$$
t^{*}=\frac{t}{D / \sqrt{g D}}
$$

Pressão adimensional

$$
p^{*}=\frac{p}{\rho u_{c}^{2}}
$$


A viscosidade característica é avaliada na taxa de cisalhamento característica, utilizando a equação de Herschel-Bulkley:

$$
\eta_{c}=k \dot{\gamma}_{c}^{n-1}+\frac{\tau_{0}}{\dot{\gamma}_{c}}
$$

Onde $\tau_{0}$ é a tensão limite de escoamento, $k$ é o índice de consistência e $n$ é o índice de comportamento do fluido.

A partir das variáveis apresentadas acima foram obtidos os parâmetros adimensionais do problema, o Número de Reynolds (Re) e Número de Bingham (Bi).

O Número de Bingham foi obtido a partir da adimensionalização da equação da função viscosidade considerando modelo Herchel-Bulkley, fazendo uso das variáveis adimensionais apresentadas ateriormente:

$$
\eta=\frac{\tau_{0}}{\dot{\gamma}}+k \dot{\gamma}^{n-1}
$$

Substituindo $\eta$ e $\dot{\gamma}$ por $\eta_{c} . \eta^{*}$ e $\dot{\gamma}_{c} \cdot \dot{\gamma}^{*}$, respectivamente, obtemos:

$$
\eta_{c} \eta^{*}=\frac{\tau_{0}}{\dot{\gamma}_{c} \dot{\gamma}^{*}}+k \dot{\gamma}_{c}^{n-1} \dot{\gamma}^{* n-1}
$$

Reorganizando a equação:

$$
\eta_{c} \eta^{*}=\frac{\tau_{0}}{\dot{\gamma}_{c}} \frac{1}{\dot{\gamma}^{*}}+k \dot{\gamma}_{c}^{n-1} \dot{\gamma}^{* n-1}
$$

Dividindo as parcelas da equação por $\eta_{c}$ :

$$
\eta^{*}=\frac{\tau_{0}}{\eta_{c} \dot{\gamma}_{c}} \frac{1}{\dot{\gamma}^{*}}+\frac{k \dot{\gamma}_{c}^{n-1}}{\eta_{c}} \dot{\gamma}^{* n-1}
$$

Definindo o valor característico da viscosidade apenas com a primeira parcela da equação (3-24), ou seja, apenas a parcela viscosa: $\eta_{c}=k \dot{\gamma}_{c}^{n-1}$, a equação (3-28) se torna:

$$
\eta^{*}=\frac{\tau_{0}}{k \dot{\gamma}_{c}^{n}} \frac{1}{\dot{\gamma}^{*}}+\dot{\gamma}^{* n-1}
$$

Definindo o parâmetro Número de Bingham (Bi) como sendo igual ao $\tau_{0}^{*}$, deste modo faz-se com que este parâmetro adimensional do problema apareça na equação da viscosidade adimensional, assim como definido por Dubash et al. (2007):

$$
\eta^{*}=B i \frac{1}{\dot{\gamma}^{*}}+\dot{\gamma}^{* n-1}
$$

O mesmo acontece com o Número de Reynolds, que aparece a partir a adimensionalização da equação de conservação de momento, como pode ser visto a seguir.

$$
\frac{\partial u^{*}}{\partial x^{*}}+\frac{\partial u^{*}}{\partial t^{*}}=\frac{1}{R e}\left(\left(B i \frac{1}{\dot{\gamma}^{*}}+\dot{\gamma}^{* n-1}\right) \frac{\partial u^{*}}{\partial x^{*}}\right)-\frac{\partial p^{*}}{\partial x^{*}}+1
$$

A equação adimensional de conservação de massa é apresentada a seguir, tendo sido obtida utilizando as variáveis adimensionais apresentadas anteriormente. 


$$
\frac{\partial \rho^{*}}{\partial \mathrm{t}^{*}}+\rho^{*}\left(\frac{\partial \mathrm{u}^{*}}{\partial \mathrm{x}^{*}}+\frac{\partial u^{*}}{\partial \mathrm{y}^{*}}\right)=0
$$

\section{5}

\section{Raio mínimo para escoamento da bolha}

Como mencionado anteriormente, uma bolha de gás irá sempre ascender devido ao empuxo, em um fluido com limite de escoamento igual a zero. Porém ela irá permanecer estacionária em um fluido viscoplástico caso a força de empuxo não seja suficiente para vencer a força de arraste. Fazendo um balanço de forças na superfície da bolha é possível encontrar um valor de raio crítico da bolha a partir do qual a mesma começa a escoar.

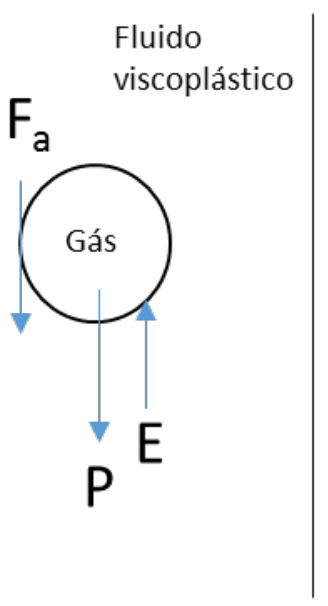

Figura 3.3: Forças atuantes na bolha de gás

A figura 3.3 ilustra as forças atuantes na bolha, onde $E$ representa a força de empuxo que atua sobre a bolha, $F_{a}$ a força de arraste e $P$ o peso da bolha de gás. Ao fazer um somatório destas forças obtemos:

$$
\sum F_{\text {bolh } a}=E-P-F_{a}=0
$$

Onde:

$$
\begin{gathered}
P=\rho_{\text {bolha }} g V_{b} \\
E=\rho_{\text {fluido }} g V_{b} \\
F_{a}=\tau_{0} A
\end{gathered}
$$

Sendo $\rho_{\text {bolha }}$ a massa específica da bolha, $\rho_{\text {fluido }}$ a massa específica do fluido, $g$ a aceleração da gravidade, $V_{b}$ o volume da bolha, $\tau_{0}$ a tensão limite de escoamento do fluido e $A$ a área da bolha. 
Substituindo as equações acima na Equação (3-33) encontra-se o raio da bolha crítico, tanto para um modelo bidimensional como para tridimensional.

A seguir é feita a substituição no caso de modelo bidimensional, ao invés de considerar o volume da bolha nas equações de peso em empuxo, considera-se a área da superfície da bolha e na equação da força de arraste ao invés de considerar a área, considera-se o perímetro, $P e$, da superfície da bolha.

$$
\rho_{\text {fluido }} g A-\rho_{\text {bolha }} g A-\tau_{0} P e=0
$$

Rearrumando a Equação (3-37) e substituindo a área da superfície da bolha por $\pi R^{2}$ e o perímetro por $2 \pi R$, onde $\mathrm{R}$ é o raio da bolha, obtemos a seguinte expressão:

$$
\left(\rho_{\text {fluido }}-\rho_{\text {bolha }}\right) g \pi R^{2}=\tau_{0} 2 \pi R
$$

Substituindo o $\rho_{\text {fluido }}$ por $1910 \mathrm{~kg} / \mathrm{cm}^{3}, \rho_{\text {bolha }}$ por $1,17 \mathrm{~kg} / \mathrm{cm}^{3}, \mathrm{~g}$ por $9,8 \mathrm{~m} / \mathrm{s}^{2}$ obtem-se o raio crítico mínimo, $R_{c}$, para bolha de gás escoando em fluido com determinado valor de tensão limite de escoamento:

$$
R_{c}=\frac{2 \tau_{0}}{\left(\rho_{\text {fluido }}-\rho_{\text {bolha }}\right) g}=\frac{2 \tau_{0}}{(1910-1,17) 9,8}
$$

Seguindo o mesmo raciocínio, substituindo a área da bolha por $4 \pi R^{2}$ e o volume da bolha por $\frac{4 \pi R^{3}}{3}$ é possível obter o raio crítico mínimo para um modelo tridimensional:

$$
R_{c}=\frac{3 \tau_{0}}{\left(\rho_{\text {fluido }}-\rho_{\text {bolha }}\right) g}=\frac{3 \tau_{0}}{(1910-1,17) 9,8}
$$

\section{6}

\section{Cálculo do coeficiente de arraste}

O coeficiente de arraste é utilizado para quantificar a resistência do fluido à ascensão da bolha de gás. Quanto maior o valor do coeficiente, maior a força de arraste que a bolha irá sofrer, dificultando seu escoamento. O cálculo do mesmo é definido pela equação abaixo:

$$
C_{d}=\frac{\tau}{\frac{1}{2} \rho v^{2}}
$$

Onde $\tau$ é a tensão cisalhante, $\rho$ é a massa específica do fluido, $v$ é a velocidade terminal da bolha.

\section{7}

\section{Cálculo do raio equivalente em domínio tridimensional}

Conforme mencionado anteriormente foi realizada uma simulação considerando uma geometria 3D a fim de validar os resultados do modelo $2 \mathrm{D}$ utilizado, 
aproximado por placas paralelas.

Para realizar a simulação em geometria tridimensional foi necessário realizar um cálculo para obter o raio equivalente da bolha neste domínio, conforme segue.

Neste cálculo foi considerando que a bolha no domínio 2D é representada por uma circunferência e que a mesma possui um "volume" representado pelo produto entre sua área e o comprimento de sua circunferência, deste modo:

$$
2 \pi R_{2 D} \cdot \pi R_{2 D}^{2}=\frac{4}{3} \pi R_{3 D}^{3}
$$

Logo:

$$
R_{3 D}=R_{2 D} \sqrt[3]{\frac{3}{2} \pi}
$$




\section{4 \\ Modelagem numérica}

\section{1}

\section{Fluidodinâmica computacional}

A fluidodinâmica computacional (CFD) pode ser usada para representar fenômenos da fluidodinâmica, termodinâmica, hidráulica, entre outros. Em muitas indústrias, onde os produtos estão relacionados diretamente com a dinâmica dos fluidos, é investido muito recurso para desenvolver novas tecnologias.

Contudo, para investir na obtenção de resultados experimentais gasta-se muito tempo e dinheiro, deste modo, vem se investindo cada vez mais em modelagem matemática e numérica para gerar resultados. Esta metodologia é mais barata e tem gerado resultados satisfatórios, porém vale destacar que não descarta a necessidade de validação experimental uma vez que os estudos se complementam.

No caso de escoamento de fluidos, o modelo matemático é estabelecido com base nas equações de conservação da quantidade de momento, massa e energia. Estas equações, quando submetidas a condições de contorno e iniciais apropriadas, representam, matematicamente, um problema particular, sendo a solução analítica destas equações somente possível para escoamentos muito simples. Para se analisar problemas reais é necessário utilizar os métodos numéricos.

No presente estudo foi utilizado o software comercial de fluidodinâmica computacional (CFD) Fluent (Ansys Inc.) para obter os resultados numéricos e resolver as equações governantes de conservação de massa e momento.

Este software fornece possibilidades de modelagem para uma vasta gama de aplicações, dentre elas a análise de escoamento de fluidos multifásicos, que é o principal interesse deste estudo.

\section{2}

\section{Método dos volumes finitos}

Para resolver numericamente as equações de conservação de massa e energia que governam o problema, o software Fluent utilizada o método dos volumes finitos. Para isto, estas equações precisam ser transformadas em sistemas de equações algébricas. A técnica de volumes finitos consiste em dividir o domínio computacional em volumes de controle e integrar temporalmente e espacialmente cada equação 
de transporte em cada volume de controle, resultando em equações discretas que expressem a lei de conservação em cada um deles.

De um modo geral, a equação de transporte a ser discretizada possui a seguinte forma:

$$
\frac{\partial \rho \phi}{\partial t}+\frac{\partial \rho u_{j} \phi}{\partial x_{j}}=\frac{\partial}{\partial x_{j}}\left(\Gamma_{\phi} \frac{\partial \phi}{\partial x_{j}}\right)+S_{\phi}
$$

Onde $\phi$ é a variável de interesse, $\Gamma_{\phi}$ é o coeficiente de difusão associado à $\phi \mathrm{e}$ $S_{\phi}$ é o termo de geração de $\phi$ por unidade de volume.

O software Fluent utiliza o método dos volumes finitos para converter uma equação geral de transporte de um escalar em uma equação algébrica que pode ser resolvida numericamente. Como visto anteriormente, este método visa integrar a equação de transporte, equação (4-1), sobre cada volume de controle, gerando uma equação de discretização que expressa a lei de conservação no volume de controle.

A discretização das equações governantes pode ser ilustrada de forma simplificada considerando a equação transiente de transporte de uma grandeza escalar genérica $\phi$. Isto é demonstrado pela equação a seguir, escrita na forma integral para o volume de controle arbitrátio V:

$$
\int_{V} \frac{\partial \rho \phi}{\partial t} d V+\oint \rho \phi \vec{v} \cdot \overrightarrow{d A}=\oint \Gamma_{\phi} \nabla \phi \cdot \overrightarrow{d A}+\int_{V} S_{\phi} d V
$$

Onde $\rho$ é a massa específica, $\vec{v}$ é o vetor velocidade $(=u \hat{i}+v \hat{j}$ em $2 \mathrm{D}), \vec{A}$ é o vetor área superficial, $\Gamma_{\phi}$ é o coeficiente de difusão para $\phi, \nabla \phi$ é o gradiente de $\phi$ $\left(=(\partial \phi / \partial x) \hat{i}+(\partial \phi / \partial y) \hat{j}\right.$ em 2D) e $S_{\phi}$ é o termo fonte de $\phi$ por unidade de volume.

A equação (4-2) é aplicada para qualquer volume de controle ou célula no domínio computacional. A célula triangular, bidimensional mostrada na Figura 4.1 é um exemplo de tal volume de controle.

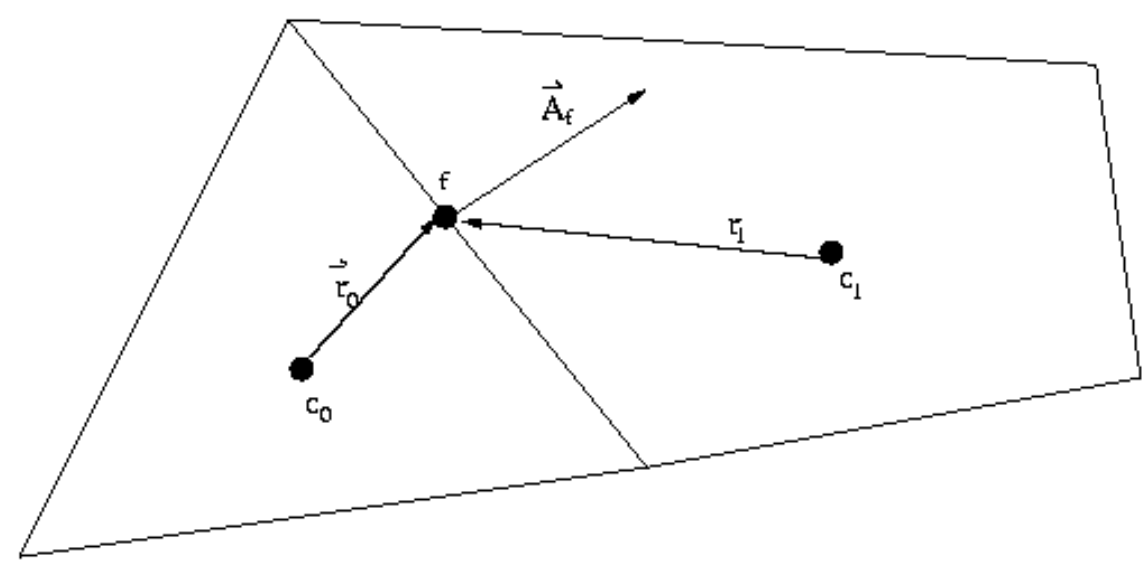

Figura 4.1: Volume de controle exemplificado para ilustrar a discretização de uma equação de transporte escalar 
A discretização da equação (4-2) em uma dada célula fornece a seguinte equação:

$$
\frac{\partial \rho \phi}{\partial t} V+\sum_{f}^{N \text { faces }} \rho_{f} \vec{v}_{f} \phi_{f} \cdot \vec{A}_{f}=\sum_{f}^{N \text { faces }} \Gamma_{\phi} \nabla \phi_{f} \cdot \vec{A}_{f}+S_{\phi} V
$$

Onde $N$ faces é o número de faces envolvendo a célula, $\phi_{f}$ é o valor de convecção através da face $f, \rho_{f} \vec{v}_{f} \cdot \vec{A}_{f}$ é o fluxo de massa através da face, $\vec{A}_{f}$ é a área da face $f, \nabla \phi_{f}$ é o gradiente de $\phi$ na face $f$ e $V$ é o volume da célula.

As equações resolvidas pelo Fluent tomam a mesma forma geral da que foi apresentada acima e é aplicavel a malhas não estruturadas multi-dimensionais compostas por poliedros arbitrários.

A equação geral de transporte de um escalar discretizada, equação (4-3), possui a variável escalar $\phi$ desconhecida no centro do volume de controle, assim como também os valores de $\phi$ são desconhecidos nas células vizinhas a este volume de controle. De um modo geral, a equação de transporte pode ser não linear. Uma forma linearizada da equação (4-3) pode ser escrita da seguinte forma:

$$
a_{P} \phi_{c_{0}}=\sum_{n b} a_{n b} \phi_{n b}+b
$$

Onde o índice $n b$ refere-se as células vizinhas, $a_{P}$ e $a_{n b}$ são os coeficientes principal e vizinhos linearizados para a solução $\phi_{c_{0}}$.

O número de células vizinhas para cada volume de controle depende da malha construída, sendo igual ao número de faces que forma o volume de controle (com exceção das células de contorno).

Deste modo, podem ser escritas equações semelhantes à equação (4-3) para cada célula na malha. Isto resulta em um sistema de equações algébricas com uma matriz de coeficiente esparsa.

O limite de tolerância para a convergência foi fixado em $1 \times 10^{-6}$ tanto para a continuidade e energia como para as velocidades nos eixos cartesianos.

\subsection{1}

\section{Discretização temporal}

No caso de simulações transientes, as equações governantes devem ser discretizadas tanto no espaço quanto no tempo. A discretização no tempo envolve a integração de cada termo das equações diferenciais em um intervalo de tempo $\Delta t$. No presente trabalho foi utilizado o esquema "first order implicit"(integração implícita de primeira ordem - Euler implítico) para discretizar os tempos transientes.

A equação (4-5) a seguir representa uma expressão genérica para a evolução no tempo de uma dada grandeza escalar $\phi$ :

$$
\frac{\partial \phi}{\partial t}=F(\phi)
$$


A variável $\Phi$ no novo instante de tempo $n+1$ é obtida avaliando a função F (que inclui qualquer discretização espacial) no instante $n+1$, então a integração implítica de primeira ordem é dada por:

$$
\phi^{n+1}=\phi^{n}+\Delta t F\left(\phi^{n+1}\right)
$$

Esta é referida como integração implícita uma vez que $\phi^{n+1}$ em uma dada célula está relacionada a $\phi^{n+1}$ em células vizinhas através de $F\left(\phi^{n+1}\right)$. Esta equação implícita deve ser resolvida iterativamente em cada intervalo de tempo antes de seguir para o próximo passo de tempo. A vantagem deste esquema é o fato de ele ser sempre estável, independente do tamanho do passo de tempo.

\subsection{2}

\section{Discretização espacial}

O Fluent possui diversos esquemas de discretização espacial para modelar os termos convectivos de cada equação governante. A seguir serão detalhados cada esquema escolhido para melhor representar o problema abordado no trabalho, resultando em uma solução mais próxima da realidade e, caso possível, com menor custo computacional.

\subsection{3}

\section{Método de cálculo dos gradientes}

Os gradientes são necessários não só para construir valores de um escalar nas interfaces das células mas também para calcular termos difusivos e derivadas da velocidade. $\mathrm{O}$ gradiente $\nabla \phi$ de uma determinada variável $\phi$ é usado para discretizar os termos convectivos e difusivos nas equações de conservação regentes do escoamento.

Para o cálculo dos gradientes no presente trabalho foi utilizado o método baseado nos mínimos quadrados (Least Square Cell Based). Este método é recomendado para malhas hexagonais e poliédricas e possui um custo computacional menor comparado aos outros disponíveis no software, por este motivo vem selecionado como padrão no Fluent.

Neste método assume-se que a solução varia linearmente. Na Figura 4.2 a mudança no valor entre as células $c_{0}$ e $c_{i}$ na direção do vetor $r_{i}$ a partir da centroide da célula $c_{0}$ para a $c_{i}$ pode ser expressa por:

$$
(\nabla \phi)_{c_{0}} \cdot \Delta r_{i}=\left(\phi_{c_{i}}-\phi_{c_{0}}\right)
$$

Se escrevermos equações similares para cada célula ao redor da célula $c_{0}$ obtemos o seguinte sistema, escrito de forma compacta:

$$
[J](\nabla \phi)_{c_{0}}=\Delta \phi
$$




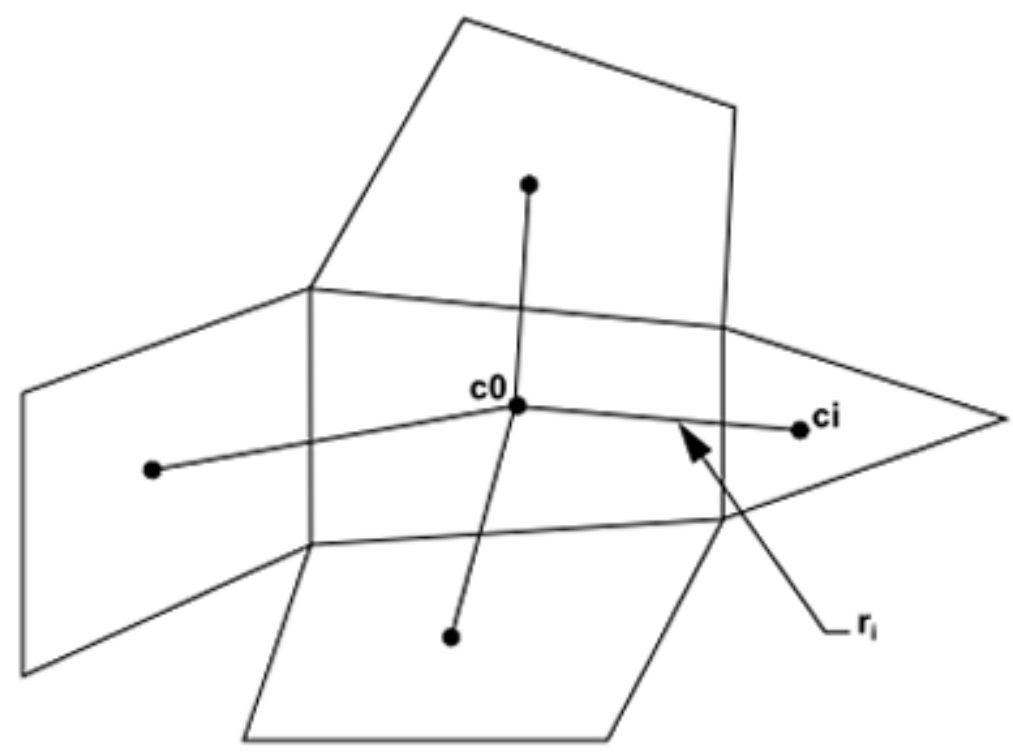

Figura 4.2: Variação no centróide das células $c_{0}$ e $c_{i}$ na direção do vetor $r_{i}$

Onde $[J]$ é a matriz de coeficientes que é puramente uma função de geometria.

Este método consiste em determinar o gradiente da célula $\left(\nabla \phi_{0}=\phi_{x} \hat{i}+\phi_{y} \hat{j}+\phi_{z} \hat{k}\right)$ ao resolver um problema de minimização para o sistema não-quadrado da matriz de coeficientes em um sentido de mínimos quadrados. $\mathrm{O}$ sistema linear de equações acima possui mais equações do que incógnitas e pode ser resolvido decompondo a matriz dos coeficientes utilizando o processo Gram-Schmidt. Esta decomposição resulta em uma matriz de pesos para cada célula. Deste modo, para nosso esquema de célula central isto significa que os três componentes de peso foram originados para cada interface da célula $c_{0}$. Assim o componente no centro da célula pode então ser computado multiplicando os fatores de peso pelo vetor diferença: $\Delta \phi=\left(\phi_{c 1}-\phi_{c 0}\right)$.

$$
\begin{aligned}
\left(\phi_{x}\right)_{c 0} & =\sum_{i=1}^{n} W^{X} i o \cdot\left(\phi_{c 1}-\phi_{c 0}\right) \\
\left(\phi_{y}\right)_{c 0} & =\sum_{i=1}^{n} W^{Y} i o \cdot\left(\phi_{c 1}-\phi_{c 0}\right) \\
\left(\phi_{z}\right)_{c 0} & =\sum_{i=1}^{n} W^{Z} i o \cdot\left(\phi_{c 1}-\phi_{c 0}\right)
\end{aligned}
$$

\subsection{4}

\section{Esquema para equação de pressão}

O método PRESTO ("Pressure Staggering Option") foi utilizando no Fluent para a discretização da equação de pressão visto que ele gera uma solução mais precisa e estável uma vez que erros de interpolação e suposições do gradiente 
de pressão nas condições de contorno são evitados, além de impedir um elevado e imprevisível aumento da velocidade nas proximidades da malha. Tal método consiste em uma interpolação da pressão ao utilizar um balanço de continuidade discreto em um volume de controle deslocado em relação à face a fim de determinar a pressão, sendo um método que requer um elevado custo computacional. Além disso, PRESTO é um dos dois únicos métodos utilizados para o modelo VOF.

\subsection{5}

\section{Esquema de discretização da equação do momento}

O esquema de discretização da equação do momento utilizado no Fluent foi o "QUICK", a fim de aumentar a ordem de precisão da discretização uma vez que este esquema é mais preciso e também por ter um custo computacional mais baixo. O esquema QUICK, "Quadratic Upstream Interpolation for the Convection Kinematics"foi proposto por Leonard (1979) e utiliza um perfil quadrático para avaliar os fluxos nas faces dos volumes de controle, sendo que dois pontos localizam-se a montante da face e um ponto à jusante. Leonard et al. (1991) otimizaram o esquema utilizando uma média ponderada das interpolações através das aproximações de Diferenças Centrais e Upwind de Segunda Ordem. Tipicamente, este esquema é mais preciso que os restantes utilizados em malhas estruturadas, sendo que possui um erro de truncamento de $3^{\text {a }}$ Ordem e os erros de falsa difusão são reduzidos significativamente. No entanto, dependendo do modo como é formulado, poderá conduzir a coeficientes da matriz de discretização negativos e a problemas de convergência.

\subsection{6}

\section{Esquema de discretização da fração volumétrica}

A formulação utilizada no Fluent para a determinação da interface entre os fluidos foi a Reconstrução Geométrica (Geo-Reconstruct), que representa a reconstrução da interface entre os fluidos utilizando uma aproximação linear, sendo a formulação mais precisa do Fluent e aplicada para malhas não estruturadas. Primeiramente, a posição linear da interface em relação ao centro de cada célula parcialmente preenchida é calculada com base na fração volumétrica na célula. Em seguida, é empregada a representação computacional linear da interface que, em conjunto com as informações sobre o campo de velocidades normais e tangenciais na face, calcula a quantidade de fluido proveniente da advecção através de cada face. Logo depois, a fração volumétrica em cada célula é calculada ao empregar um balanço de fluxos calculado nas etapas anteriores. De forma resumida, a Reconstrução Geométrica supõe que a interface entre os fluidos tem uma inclinação linear com cada célula, usando essa distorção linear para calcular a advecção do fluido através da face da célula. Este esquema foi escolhido pois torna a interface entre 
os fluido clara e nítida, sem difusão numérica e pelo fato de fornecer um resultado mais preciso.

\section{3}

\section{Acoplamento Velocidade-Pressão}

O Fluent está munido de métodos que auxiliam na melhoria da convergência da equação de conservação de massa e momento, à qual estão acopladas a velocidade e pressão. Este software possui três importante métodos: SIMPLE, SIMPLEC e PISO. O esquema PISO é altamente recomendado para cálculos de regime transiente e atinge a convergência de um modo mais rápido e eficaz, reduzindo o tempo de cálculo da solução, por estes motivos foi selecionado para o presente trabalho.

O algoritmo PISO ("Pressure-Implicit with Splitting of Operators"), desenvolvido por Issa (1986) é fortemente recomendado para todos os fluxos transientes e é considerado uma extensão do algoritmo SIMPLE. O mesmo consiste em gerar uma solução mais aproximada da correção da pressão do que o algoritmo SIMPLE e os demais algoritmos ao empregar dois níveis de correção ("Skeweness Correction"e "Neighbor Correction"), podendo manter um cálculo estável para um passo de tempo elevado e para um fator de relaxamento inferior a 1,0 tanto para o momento quanto para a pressão. A vantagem dele em relação aos algoritmos SIMPLE e SIMPLEC é baseada no fato de a convergência por passo de tempo ser alcançada com um número consideravelmente menor de iterações apesar de o tempo requerido para uma iteração ser maior.

O algoritmo PISO se baseia na seguinte sequência de etapas: primeiramente, as condições de contorno são definidas e as equações de momento discretizadas são resolvidas obtendo-se um perfil de velocidades. Em seguida, a equação de correção da pressão é resolvida, obtendo-se até esta etapa valores de pressão e velocidade. O próximo passo consiste na solução da segunda equação de correção da pressão, tendo como resultado novos valores de pressão e velocidade. A seguir, todas as outras equações de transporte discretizadas são resolvidas. Caso ocorra convergência, o processo é finalizado. Caso contrário, o processo é reiniciado.

\section{4}

\section{Método VOF}

Como mencionado anteriormente, o método VOF (volume of fluid) foi utilizado para modelar o escoamento dos dois fluidos, resolvendo um sistema de equações de momento e localizando onde cada um dos fluidos imiscíveis entre si possui a fração volumétrica desejada. Por exemplo, ele pode localizar a interface entre estes dois fluidos, ou seja, a região onde os mesmos possuem fração volumétrica igual a 0,5. Esta localização das interfaces entre cada fase é representada pela equação da 
continuidade para a fração volumétrica de uma das fases. Ressaltando que a fração volumétrica de um fluido é dada pela razão entre o volume ocupado por este fluido e o volume ocupado pela mistura, sendo simbolizada pela letra $\alpha$.

\section{5}

\section{Fatores de sub-relaxação}

Por causa da não linearização das equações é necessário controlar a mudança da variável genérica $\phi$. Isto é obtido através da sub-relaxação, de forma a reduzir a mudança de $\phi$ produzida durante cada iteração, conforme a equação a seguir:

$$
\phi=\phi_{\text {old }}+\alpha \Delta \phi
$$

Onde $\phi$ é o novo valor da variável dentro de uma célula, $\phi_{\text {old }}$ é o valor anterior de $\phi, \Delta \phi$ é a mudança computada em $\phi$ e $\alpha$ é o fator de sub-relaxação.

No Fluent são definidos parâmetros de sub-relaxação padrões para todas as variáveis, que estão próximo do valor ótimo na maioria dos casos. Estes valores são adequados na maioria dos casos, porém para alguns problemas particulares é necessário reduzir um ou outro fator inicialmente. No presente trabalho foi necessário reduzir somente o fator de sub-relaxação da equação de energia sendo os outros mantidos o padrão do programa. A Figura 4.3 mostra os fatores utilizados para cada variável:

Pressure
\begin{tabular}{|l|}
\hline 0.3 \\
\hline Density \\
\hline 1 \\
\hline Body Forces \\
\hline 1 \\
\hline Momentum \\
\hline 0.7 \\
\hline Energy \\
\hline 0.7 \\
\hline
\end{tabular}

Figura 4.3: Fatores de sub-relaxação utilizados para pressão, densidade, forças de corpo, equação de momento e pressão.

\section{6}

\section{Modelo Herschel-Bulkley regularizado}

O software ANSYS Fluent define uma versão regularizada do modelo de Herschel-Bulkley para que seja possível resolver a equação numericamente, substituindo a região de viscosidade infinita (ou taxa de deformação nula) por uma região 
de viscosidade muito elevada e alterando a transição descontínua entre as duas regiões por uma transição contínua.

Enquanto o modelo Herschel-Bulkley é usualmente definido conforme a equação previamente descrita (3-4), a regularização é dada pela seguinte equação:

$$
\eta=\left\{\begin{array}{cr}
\frac{\tau_{0}}{\dot{\gamma}}+k\left(\frac{\dot{\gamma}}{\dot{\gamma}_{c}}\right)^{n-1} & \text { quando } \dot{\gamma}>\dot{\gamma}_{c} \\
\tau_{0} \frac{\left(2-\dot{\gamma} / \dot{\gamma}_{c}\right)}{\dot{\gamma}_{c}}+k\left[(2-n)+(n-1) \frac{\dot{\gamma}}{\dot{\gamma}_{c}}\right] & \text { quando } \dot{\gamma} \leq \dot{\gamma}_{c}
\end{array}\right.
$$

Onde $\dot{\gamma}_{c}$ é a taxa de cisalhamento crítica [1/s].

\section{7}

\section{Teste de malha}

A solução numérica foi modelada considerando uma seção do espaço anular entre um poço de 12 1/4"e o revestimento de 9 5/8", aproximando o problema para placas paralelas. Foi utilizada uma malha estruturada, conforme pode ser visto na Figura 4.4, com 690 divisões na direção axial e 69 na direção radial, o que leva a 47.610 células. A qualidade da malha foi testada e considerada satisfatória tanto para ortogonalidade quanto para assimetria.

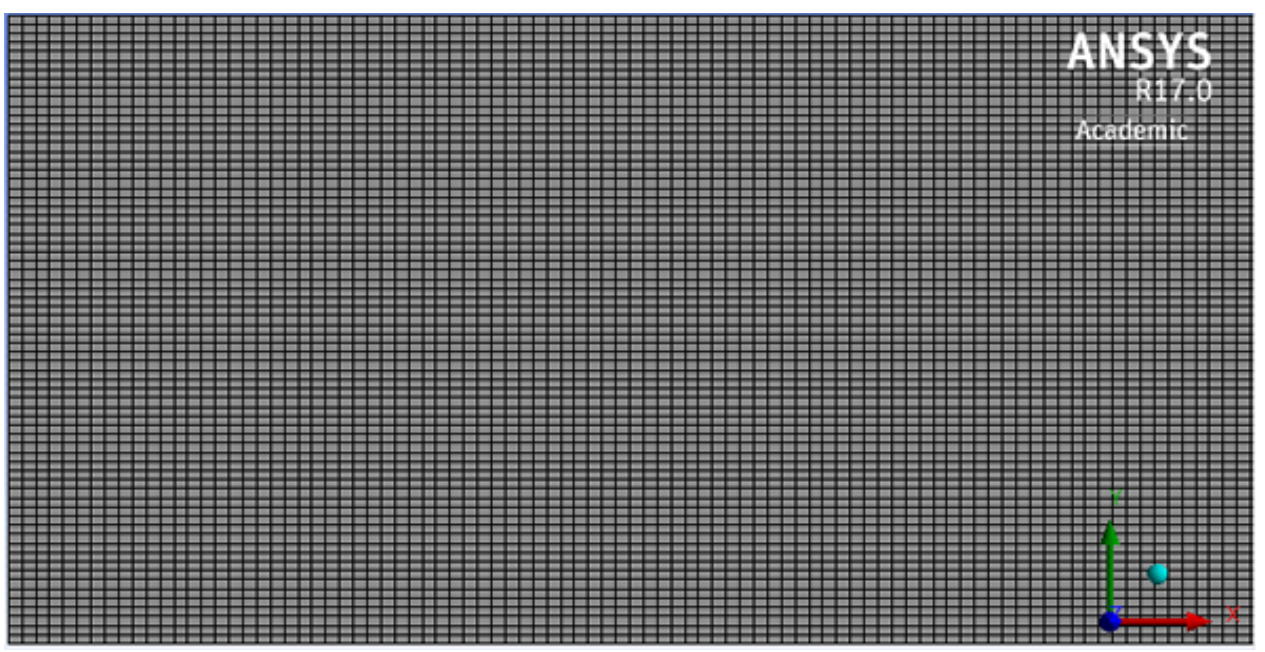

Figura 4.4: Malha estruturada

Com a finalidade de identificar esta malha como a mais adequada para o problema, foi realizado um teste de malha, comparando os resultados dos seus efeitos na velocidade de subida de uma bolha de gás de diâmetro igual a 0,02m. Foram testadas 3 malhas diferentes, conforme segue: malha A com com 600 divisões na direção axial e 60 na direção radial, malha B, 15\% mais refinada que a malha A, com 690 divisões na direção axial e 69 na direção radial e malha C, 35\% mais refinada que a malha $\mathrm{A}$, com 810 divisões na direção axial e 81 na direção radial. Estes testes foram realizados considerando fluido não newtoniado, utilizando 
o modelo Herschel-Bulkley regularizado com as seguintes propriedades: Massa específica: $1910 \mathrm{~kg} / \mathrm{m}^{3}$, tensão limite de escoamento: $2 \mathrm{~Pa}$, índice de consistência: 1 $\mathrm{kg} / \mathrm{m}^{-s}$, índice de comportamento do fluido: 0,7 e tensão interfacial de entre fluidos: $0,07 \mathrm{~N} / \mathrm{m}$.

A Figura 4.5 mostra um gráfico que demonstra o efeito das malhas na velocidade de subida da bolha, é possível observar que a velocidade de subida da bolha na malha $\mathrm{B}$ é muito próxima da velocidade da bolha na malha $\mathrm{C}$, quantitativamente esta diferença é de apenas 3\%, o que não justifica a utilização de uma malha tão refinada quanta a malha $\mathrm{C}$, que gera um custo computacional muito superior. Deste modo, a malha B, contendo 690 divisões na direção axial e 69 na direção radial, foi adotada no presente estudo levando em consideração o custo computacional e também o consumo de tempo para cada simulação.

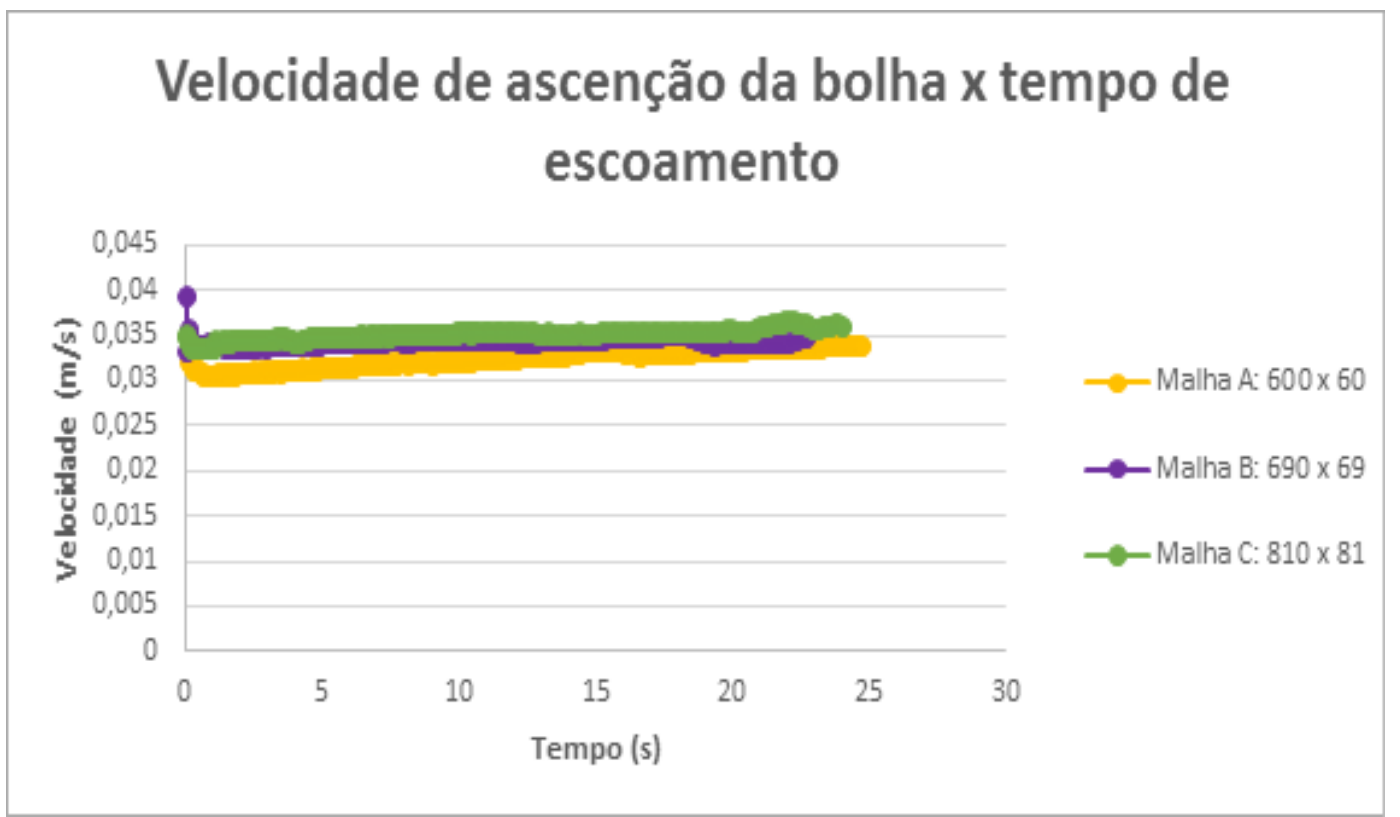

Figura 4.5: Efeito da malha na velocidade de ascenção da bolha

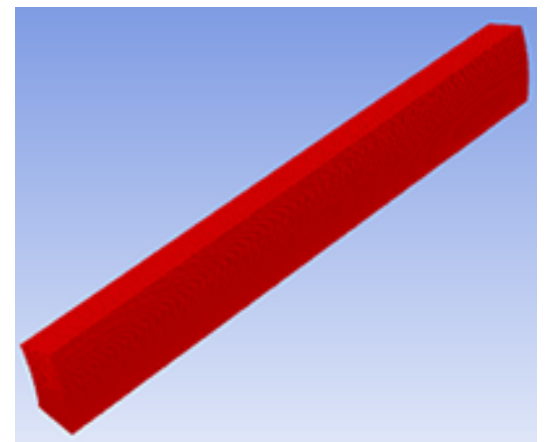

Figura 4.6: Malha estruturada em geometria 3D 
Como mencionado anteriormente, também foi realizada uma simulação considerando uma geometria tridimensional. A mesma foi feita considerando-se apenas uma fatia do cilindro, como pode ser visto na Figura 4.6, a fim de tornar a simulação possível uma vez que o custo computacional com este domínio é muito alto. $\mathrm{Na}$ simulação foi utilizada uma malha estruturada, com 80 divisões na direção radial, 200 na direção tangencial e 100 na direção axial, o que leva a 1.600 .000 células. Não foi feito um teste de malha neste domínio devido ao longo tempo que seria despendido para tal. A simulação foi realizada apenas para validar o modelo 2D.

\section{8}

\section{Condições de contorno}

Antes de começar a simulação, foi considerada uma condição inicial na qual foi inserida uma bolha no início do domínio onde a mesma possuía velocidade nula, assim como o fluido naquele instante inicial.

A definição correta das condições de contorno é fundamental para a obtenção de resultados coerentes para o problema analisado. No presente trabalho foram consideradas as seguintes condições de contorno: entrada do escoamento - condição "wall", saída do escoamento - condição "pressure outlet"e nas laterais superior e inferior do domínio - condição "wall". Cada uma destas condições será descrita mais detalhadamente a seguir e as mesmas foram identificadas na Figura 4.7.

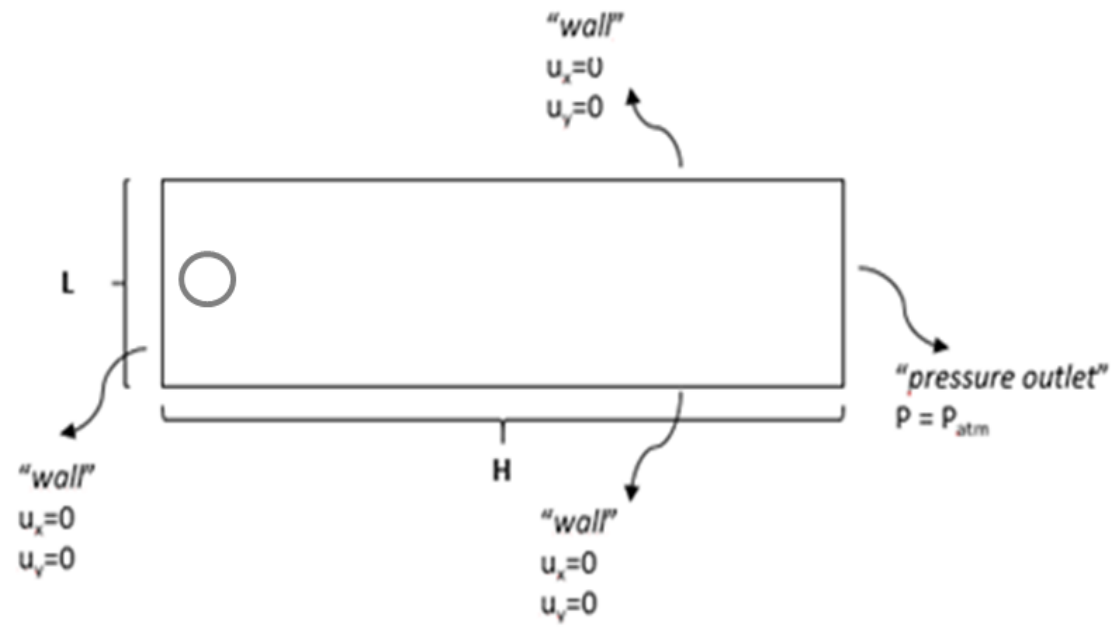

Figura 4.7: Condições de contorno do problema

No caso do presente trabalho, esta condição pode ser representada pelas seguintes equações:

$$
\begin{aligned}
& u_{x}(x=0, y)=0 \\
& u_{y}(x=0, y)=0
\end{aligned}
$$




\subsection{1}

\section{Condição pressure outlet}

Esta condição de contorno requer a especificação da pressão estática na borda de saída do escoamento, aonde foi definida a condição de pressão atmosférica. Quando ocorre fluxo reverso durante a iteração, a utilização de "pressure outlet"resulta em uma melhor taxa de convergência quando comparado com a condição de contorno de "outflow condition".

No presente trabalho esta condição pode ser representada por:

$$
P(x=H, y)=P_{a t m}
$$

\subsection{2}

\section{Condição wall}

Esta condição de contorno é utilizada para identificar quais regiões se comportam como parede, que no caso que estamos simulando, aproximando para placas paralelas, são as paredes laterais, sendo uma a parede do poço e a outra o revestimento e também a região do "fundo"do poço onde foi considerado que o fluido teria velocidade nula em todas as direções. Foi selecionada a opção "parades estacionárias"pois as mesmas não estão em movimento e "no slip"que é a condição de não deslizamento, ou seja, considerando que o fluido em contato com a superfície sólida possui velocidade nula em relação à mesma.

Esta condição pode ser representada pelas seguintes equações:

$$
\begin{aligned}
& u_{x}(x, y=0)=0 \\
& u_{y}(x, y=L)=0
\end{aligned}
$$




\section{Resultados}

Após terem sido definidas as dimensões do domínio de interesse, feito o refinamento da malha e escolhidas as condições de contorno mais adequadas ao problema foram simulados diferentes casos variando determinados parâmetros a fim de verificar suas influências no escoamento da bolha de ar no fluido viscoplástico considerado. Os parâmetros analisados foram: tensão limite de escoamento, dimensão da bolha, número de bolhas escoando e distância entre as bolhas.

A seguir serão apresentados resultados gráficos com a finalidade de explicar as mudanças no comportamento da(s) bolha(s) ao variar os parâmetros citados acima.

\section{1}

\section{Análise do escomento de uma bolha}

Como mencionado anteriormente, o presente trabalho contempla simulações numéricas considerando o escoamento de apenas uma bolha em fluido viscoplástico e também simulações considerando escoamento de mais de uma bolha a fim de verificar a interferência entre elas. Nesta primeira seção serão analisados os resultados para o fluxo de uma bolha e posteriormente o resultado com múltiplas bolhas.

\subsection{1}

\section{Influência da dimensão da bolha nos resultados}

Foram simulados 13 casos, considerando a malha e dimensões do domínio informados no capítulo anterior, variando-se o raio da bolha de ar que escoa no fluido viscoplástico com massa específica de $1910 \mathrm{~kg} / \mathrm{m}^{3}$ e com os seguintes parâmetros reológicos: índice de consistência $(\mathrm{k})=1 \mathrm{~kg} / \mathrm{m}^{-s}$, índice de comportamento do fluido $(n)=0,7$. Foi considerada uma tensão interfacial entre os fluidos de 0,07 $\mathrm{N} / \mathrm{m}$. A Tabela 5.1 resume os 13 casos simulados para dois diferentes valores de tensão limite de escoamento: $\tau_{0}=2 \mathrm{~Pa}$ e $\tau_{0}=4 \mathrm{~Pa}$.

Uma vez que as bolhas começam a escoar no fluido elas aceleram no sentido ascendente até atingir uma velocidade terminal aproximadamente constante. Esta velocidade foi computada para cada um dos casos apresentados acima e com estes valores foi possível plotar um gráfico de velocidade versus raio da bolha como pode 


\begin{tabular}{|c|c|c|c|c|c|c|c|}
\hline$\tau_{0}(\mathrm{~Pa})$ & Caso & \begin{tabular}{|c|} 
Raio da bolha \\
$(\mathrm{m})$
\end{tabular} & $d / L$ & $\tau_{0}(\mathrm{~Pa})$ & Caso & \begin{tabular}{|c|} 
Raio da bolha \\
$(\mathrm{m})$
\end{tabular} & $d / L$ \\
\hline \multirow{13}{*}{2} & $1 \mathrm{~A}$ & 0,001 & 0,06 & \multirow{13}{*}{4} & $1 \mathrm{~A}$ & 0,001 & 0,06 \\
\hline & $1 \mathrm{~B}$ & 0,0015 & 0,09 & & $1 \mathrm{~B}$ & 0,0015 & 0,09 \\
\hline & $1 \mathrm{C}$ & 0,002 & 0,12 & & $1 \mathrm{C}$ & 0,002 & 0,12 \\
\hline & $1 \mathrm{D}$ & 0,0025 & 0,15 & & $1 \mathrm{D}$ & 0,0025 & 0,15 \\
\hline & $1 \mathrm{E}$ & 0,003 & 0,18 & & $1 \mathrm{E}$ & 0,003 & 0,18 \\
\hline & $1 \mathrm{~F}$ & 0,0035 & 0,21 & & $1 \mathrm{~F}$ & 0,0035 & 0,21 \\
\hline & $1 \mathrm{G}$ & 0,004 & 0,24 & & $1 G$ & 0,004 & 0,24 \\
\hline & $1 \mathrm{H}$ & 0,0045 & 0,27 & & $1 \mathrm{H}$ & 0,0045 & 0,27 \\
\hline & 11 & 0,005 & 0,30 & & 11 & 0,005 & 0,30 \\
\hline & 11 & 0,0055 & 0,33 & & 11 & 0,0055 & 0,33 \\
\hline & $1 \mathrm{~K}$ & 0,00575 & 0,35 & & $1 \mathrm{~K}$ & 0,00575 & 0,35 \\
\hline & $1 \mathrm{~L}$ & 0,006 & 0,36 & & $1 \mathrm{~L}$ & 0,006 & 0,36 \\
\hline & $1 \mathrm{M}$ & 0,0065 & 0,39 & & $1 \mathrm{M}$ & 0,0065 & 0,39 \\
\hline
\end{tabular}

Tabela 5.1: Relação de simulações realizadas variando-se o raio da bolha para diferentes valores de tensão limite de escoamento

ser visto na Figura 5.1. Como esperado as bolhas menores sofrem maior resistência ao fluxo, o que vai diminuindo a medida em que a bolha cresce.

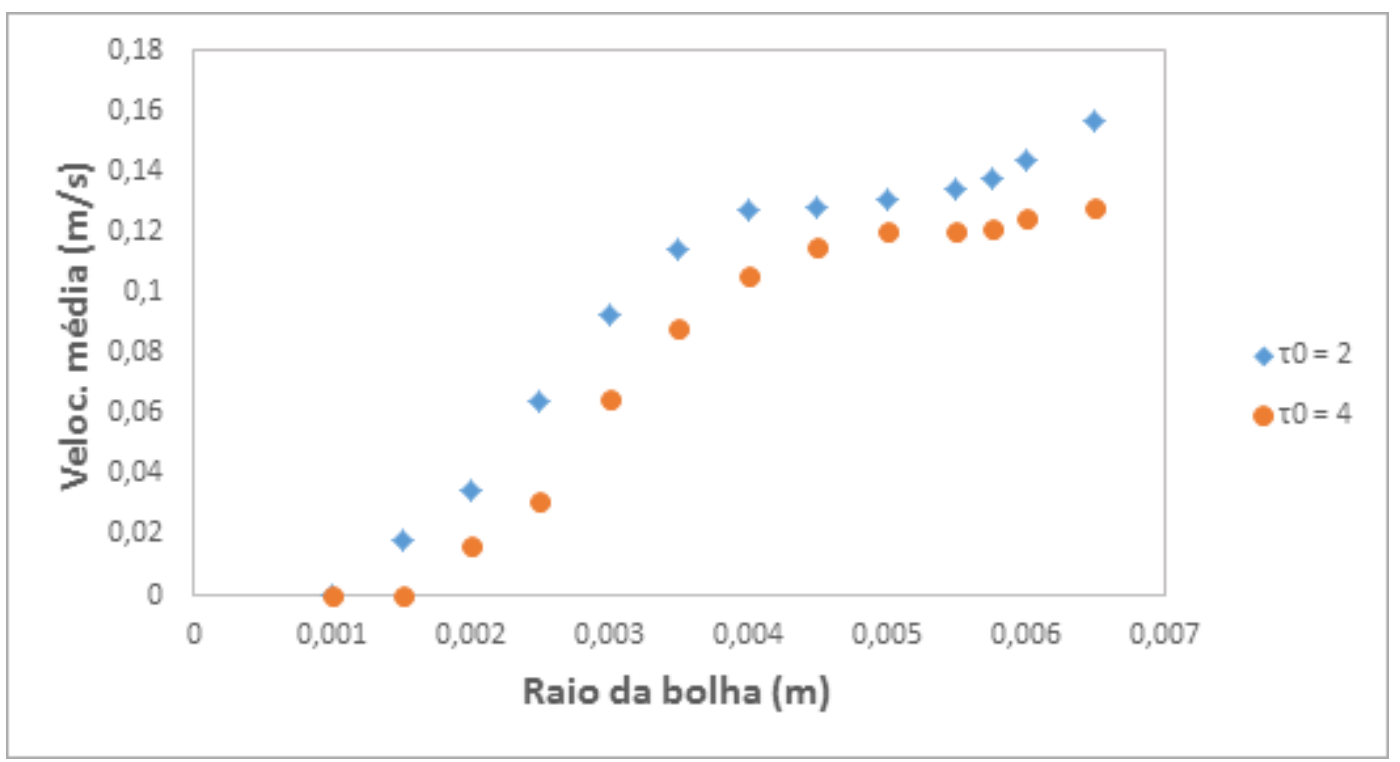

Figura 5.1: Relação entre a velocidade média da bolha e seu raio máximo

A partir deste gráfico pode-se observar que bolhas com raio menor do que 0,001 m permanecem praticamente imóveis no fluido, ou seja, a força de empuxo apesar de ser suficiente para vencer a tensão limite de escoamento ainda é muito baixa pois o volume da bolha é menor, fazendo com que ela se movimente muito lentamente. No caso de raio da bolha igual a $1 \times 10^{-2} \mathrm{~m}$ foi verificada uma velocidade 
média de aproximadamente $2,2 \times 10^{-4} \mathrm{~m} / \mathrm{s}$ para escoamento em fluido com tensão limite de escoamento igual a $2 \mathrm{~Pa}$ e de aproximadamente $5,8 \times 10^{-6} \mathrm{~m} / \mathrm{s}$ no caso fluido com tensão limite de escoamento igual a $4 \mathrm{~Pa}$, esta diferença se deve ao fato de que os níveis de viscosidade serão menores em fluidos com tensão limite de escoamento menor, facilitando o escoamento uma vez que o arraste será menor.

Utilizando as equações 40 e 41 , respectivamente para um modelo bi e tridimensional, foi possível calcular o raio crítico a partir do qual a bolha começa a se movimentar, para os dois diferentes valores de tensão limite de escoamento considerados nos casos simulados. A Tabela 5.2 resume os valores calculados.

\begin{tabular}{|ccc|}
\hline $\begin{array}{c}\mathbf{\tau}_{0} \\
(\mathbf{P a})\end{array}$ & $\begin{array}{c}\mathbf{R}_{\mathbf{c}}-\text { modelo 2D } \\
(\mathbf{m})\end{array}$ & $\begin{array}{c}\mathbf{R}_{\mathbf{c}}-\text { modelo 3D } \\
(\mathbf{m})\end{array}$ \\
\hline 2 & $2 \times 10^{-4}$ & $3 \times 10^{-4}$ \\
4 & $4 \times 10^{-4}$ & $6 \times 10^{-4}$ \\
\hline
\end{tabular}

Tabela 5.2: Raio crítico para $\tau_{0}$ igual a 2 e $4 \mathrm{~Pa}$

A partir dos valores de velocidade observados para bolhas escoando com raio igual a $1 \times 10^{-3} \mathrm{~m}$, conforme comentado anteriormente, pode-se concluir que bolhas com raio entre este valor e os valores calculados de raio crítico tanto para $\tau_{0}$ igual a $2 \mathrm{~Pa}$ quanto $4 \mathrm{~Pa}$, se movem muito lentamente, permanecendo quase que imóvel ao se aproximar do raio crítico e abaixo deste valor ela não se move mais uma vez que não possui mais força de empuxo suficiente para vencer as forças viscosas do fluido. Vale destacar que, conforme mencionado anteriormente, o modelo de HerschelBulkley utilizado é um modelo regularizado e por este motivo serão observadas velocidades não nulas para as bolhas, mesmo que sejam menores que o raio crítico.

\section{1 .2}

\section{Influência da parade nos resultados}

Ao observar o gráfico da Figura 5.1 também é possível verificar que a partir de certo ponto a velocidade tende a estabilizar ao aumentar o raio da bolha e em um certo momento ela dá um pico e volta a aumentar. Para verificar se este comportamento era devido ao efeito da parede foram feitas novas simulações para os casos $1 \mathrm{C}, 1 \mathrm{E}, 1 \mathrm{G}, 1 \mathrm{I}$ e $1 \mathrm{M}$, para $\tau_{0}=2$, considerando um anular (no caso a distância entre as placas) duas vezes maior, ou seja, com largura de 0,066 m e assim foram feitas comparações com as velocidades médias obtidas com o anular original de largura 0,033 m. Para a simulação com este anular maior de largura 0,066 a malha utilizada foi considerada dobrando a quantidade de divisões neste sentido em relação a malha original. O gráfico da Figura 5.2 representa o comparativo entre os resultados destas novas simulações com um anular maior e as simulações originais. 


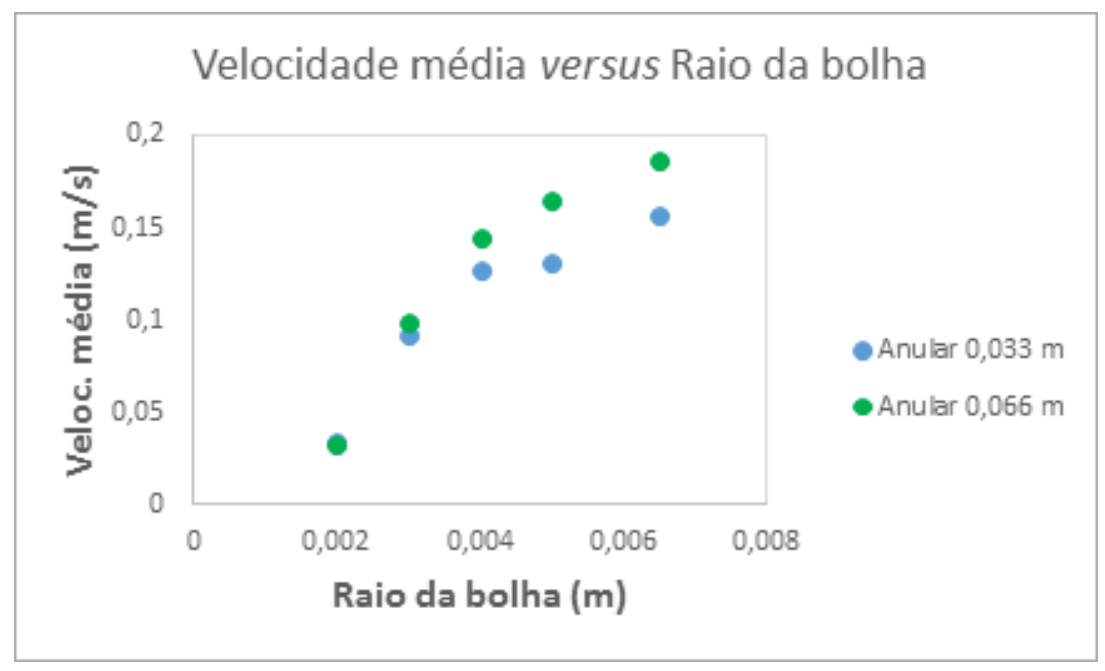

Figura 5.2: Comparativo entre simulações com anular de 0,033 m e 0,066 m

Analisando o gráfico da Figura 5.2 pode-se perceber que os efeitos da parede começam a ser significativos a partir de um raio de bolha de $0,004 \mathrm{~m}$, para bolhas menores os efeitos da parede parecem não influenciar. Esta conclusão também pode ser comprovada comparando-se os campos de taxa de deformação e velocidade para os raios de bolha iguais a 0,002, 0,003 e 0,004 m, conforme Figuras 5.3 e 5.4.

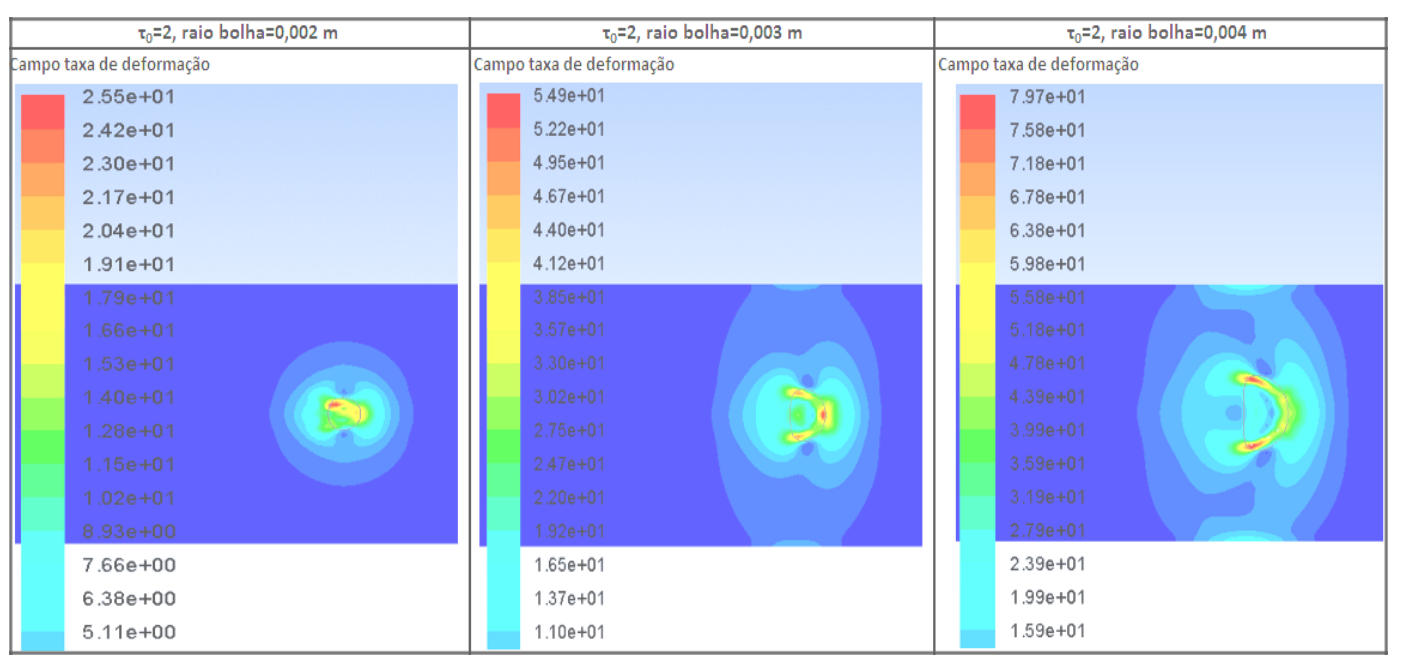

Figura 5.3: Campo taxa de deformação para bolhas escoando em anular de 0,033 m

Nas Figuras 5.3 e 5.4 é possível perceber que a parede não influencia no escoamento de bolhas pequenas, com diâmetro menor do que $0,003 \mathrm{~m}$. A partir de 0,003 m esta começa a sofrer uma pequena influência da parede, o que pode ser observado através do campo taxa de deformação e comprovado no gráfico da Figura 5.2 ao se comparar as velocidades de escoamento da bolha nos dois anulares, percebe-se que há uma pequena diferença entre elas. Já no caso do escoamento da bolha de raio $0,004 \mathrm{~m}$ esta influência é mais significativa, podendo ser visto no 


\begin{tabular}{|c|c|c|}
\hline$\tau_{0}=2$, raio bolha $=0,002 \mathrm{~m}$ & $\tau_{0}=2$, raio bolha $=0,003 \mathrm{~m}$ & $\tau_{0}=2$, raio bolha $=0,004 \mathrm{~m}$ \\
\hline campo velocidade & Campo velocidade & Campo velocidade \\
\hline $2.87 \mathrm{e}-02$ & $9.33 \mathrm{e}-02$ & $1.21 \mathrm{e}-01$ \\
\hline $2.73 \mathrm{e}-02$ & $8.86 \mathrm{e}-02$ & $1.15 \mathrm{e}-01$ \\
\hline $2.58 \mathrm{e}-02$ & $8.40 \mathrm{e}-02$ & $1.09 \mathrm{e}-01$ \\
\hline $2.44 \mathrm{e}-02$ & $7.93 \mathrm{e}-02$ & $1.03 \mathrm{e}-01$ \\
\hline $2.30 \mathrm{e}-02$ & $7.46 \mathrm{e}-02$ & $9.65 \mathrm{e}-02$ \\
\hline $2.15 \mathrm{e}-02$ & $7.00 \mathrm{e}-02$ & $9.05 \mathrm{e}-02$ \\
\hline $\begin{array}{l}1.58 \mathrm{e}-02 \\
1.44 \mathrm{e}-02\end{array}$ & $.660-02$ & D \\
\hline $8.61 \mathrm{e}-03$ & $2.80 \mathrm{e}-02$ & $3.62 \mathrm{e}-02$ \\
\hline $7.18 \mathrm{e}-03$ & $2.33 \mathrm{e}-02$ & $3.02 \mathrm{e}-02$ \\
\hline $5.74 \mathrm{e}-03$ & $1.87 \mathrm{e}-02$ & $2.41 \mathrm{e}-02$ \\
\hline
\end{tabular}

Figura 5.4: Campo velocidade para bolhas escoando em anular de 0,033 m

campo de taxa de deformação e velocidade e comprovado através da diferença mais significativa, em torno de $12 \%$ entre as velocidades nos diferentes anulares.

Ao comparar o comportamento no final das curvas da Figura 5.1 para $\tau_{0}=2$ e $\tau_{0}=4$ pode-se também verificar que se comportam de maneira diferente, para $\tau_{0}$ $=2$ o salto do pico de velocidade é maior do que para $\tau_{0}=4$. Isto se deve ao fato de que os efeitos da parede são sentidos mais rapidamente em fluidos com tensão limite de escoamento menor, como pode ser visto na Figura 5.5.

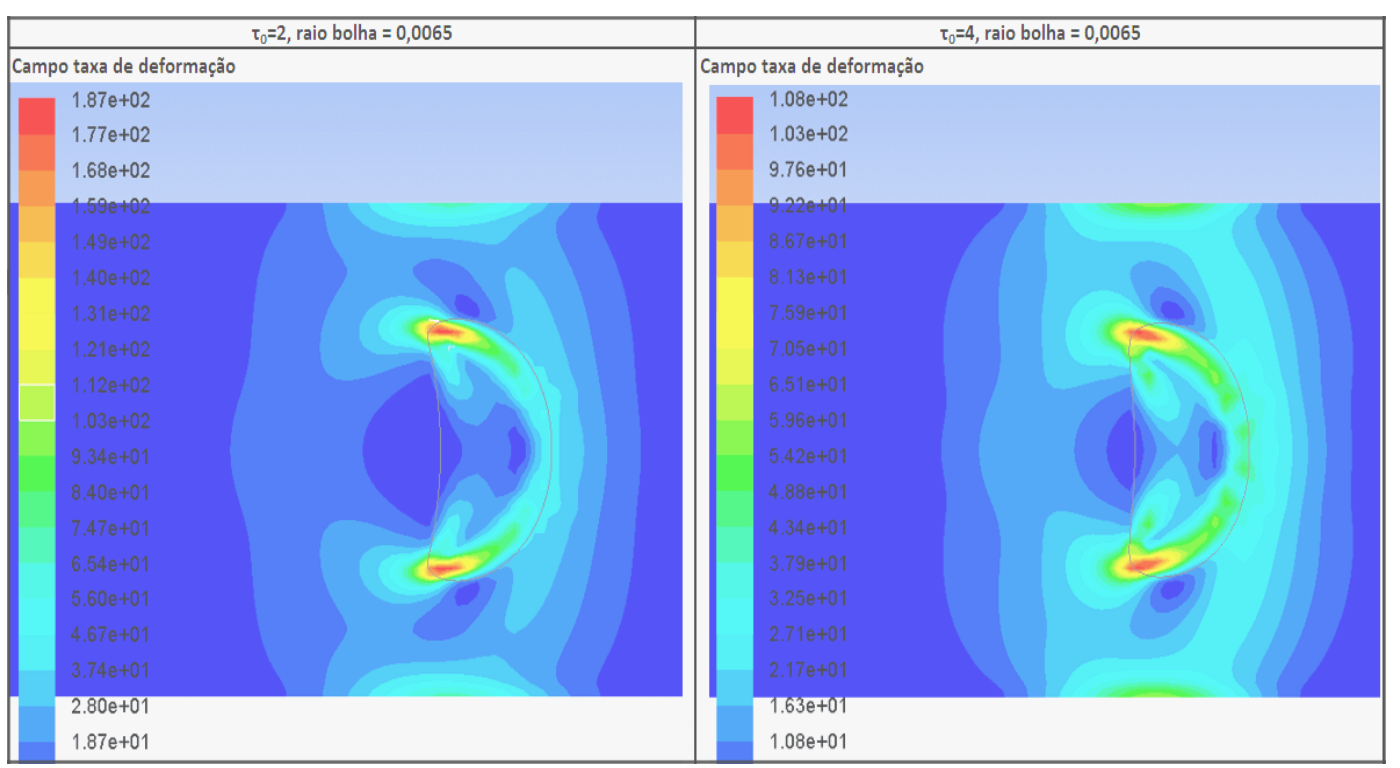

Figura 5.5: Campos taxa de deformação para $\tau_{0}=2$ e $\tau_{0}=4$ considerando raio da bolha igual a $0,0065 \mathrm{~m}$

A Figura 5.5 mostra os campos de taxa de deformação para o caso $1 \mathrm{M}$ tanto para $\tau_{0}=2$ quanto para $\tau_{0}=4$. Analisando quantitativamente é possível perceber 
que o nível de taxa de deformação é mais elevado no caso de $\tau_{0}=2$, logo este acaba sentindo mais o efeito da parede.

\subsection{3}

\section{Análise do formato da bolha}

A Figura 5.6 mostra a mesma relação entre os dados velocidade versus dimensão da bolha plotados agora na forma adimensional, onde $d / L$ representa a razão entre o diâmetro da bolha e a distância entre as placas.

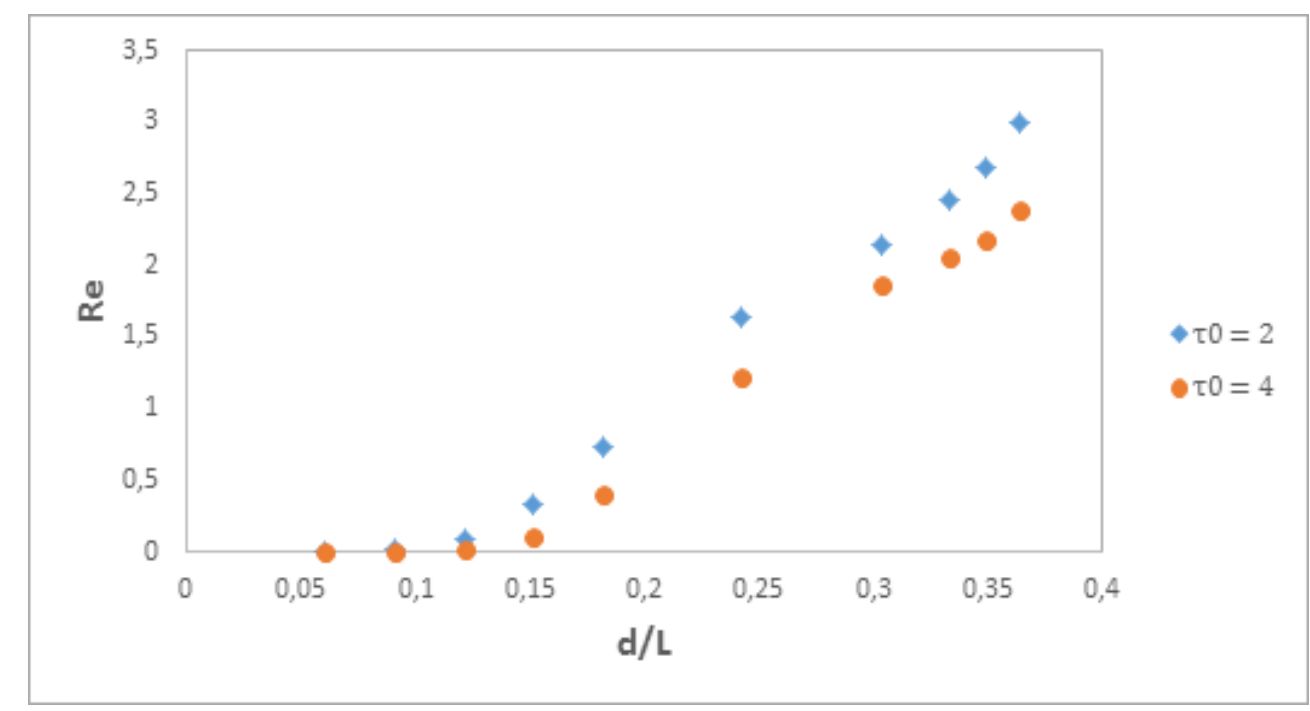

Figura 5.6: Relação entre o número de Reynolds generalizado e a dimensão da bolha

Neste caso, a partir da velocidade média da bolha foi calculado o número de Reynolds generalizado, conforme Equação (3-25), mesmo utilizado no estudo de D. Sikorski et al (2009).

$$
R e=\frac{2 \rho v_{\text {média }} R_{\max }}{\eta}
$$

Onde $\rho$ é a massa específica do fluido, $v_{m e ́ d i a}$ é a velocidade média da bolha, $R_{\max }$ é o raio máximo da bolha e $\eta$ é a viscosidade do material, a qual é calculada a partir da Equação (5-1).

$\mathrm{Na}$ Figura 5.7 foram selecionados alguns valores de Re do gráfico da Figura 5.6 para a curva de $\tau_{0}=2$ a fim de visualizar a evolução do formato da bolha em função do número de Reynolds.

Pode-se obervar que quando o número de Reynolds é mais baixo o formato da bolha é esférico e a medida em que o número de Reynolds vai aumentando esta bolha vai se deformando e adquire uma forma de elipsoidal. Este resultado representa adequadamente o esperado através da literatura, uma vez que para bolhas suficientemente pequena, as forças de tensão superficial tenderão a manter o formato aproximadamente esférico. A medida que a bolha cresce, as forças de 


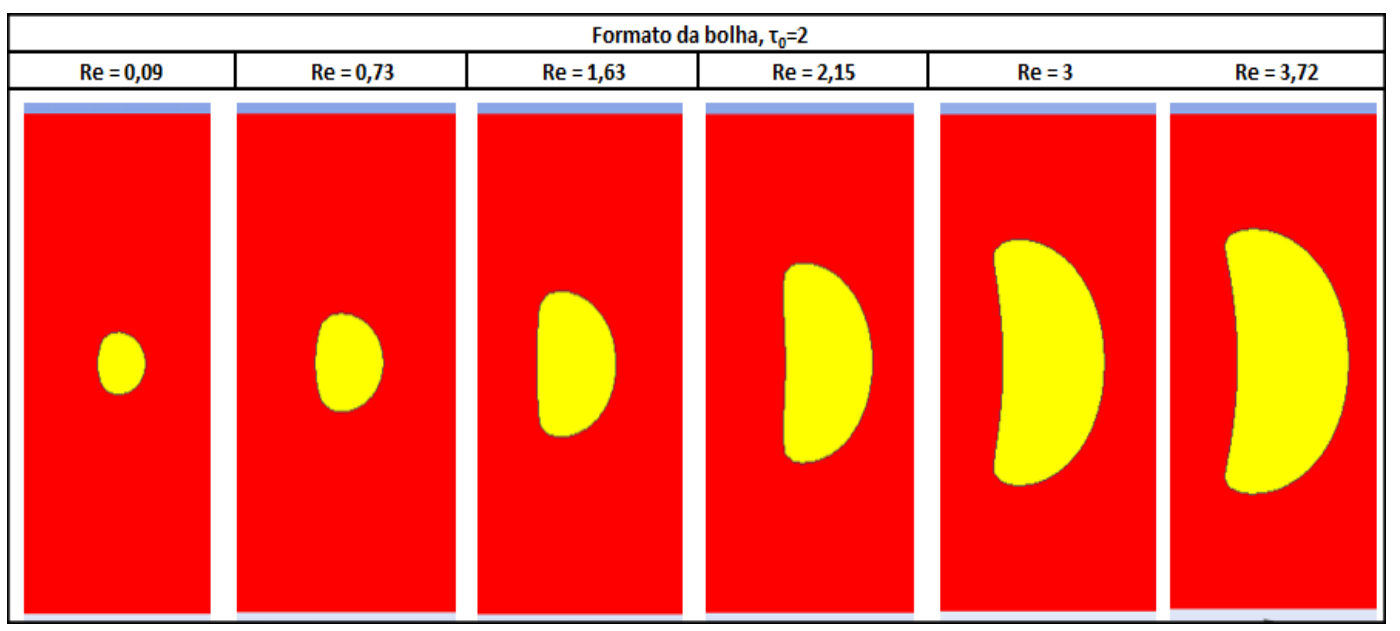

Figura 5.7: Evolução do formato da bolha para diferentes número de Reynolds

inércia aumentam e superam a tensão interfacial, esta última se torna relativamente sem importância para determinar o formato da bolha. Dependendo do tamanho da bolha e dos valores das propriedades físicas da fase contínua, é possível observar uma transição significativa no formato da bolha, como foi observado no presente estudo.

Esta evolução de formato da bolha vai contra os resultados encontrados por Bruyn et al. (2009), onde foi observado um formato de gota invertida com uma cabeça arredondada e cauda mais afunilada. Porém em seu experimento foi utilizado fluido Carbopol e as tensões limite de escoamento foram de 24 e $34 \mathrm{~Pa}$, bem superior aos valores usados no presente estudo numérico. Foi suspeitado que a elasticidade pode afetar significativamente a fluidodinâmica do Carbopol, fator que não é considerado nas simulações realizadas. Por outro lado, os resultados encontrados aqui vão de encontro aos resultados simulados no trabalho de Dimakopoulos et al. (2013) e os possíveis motivos da diferença entre os formatos encontrados nestes dois estudos já foram citados no capítulo 2.

Em relação a trajetória de ascensão das bolhas, pode ser observado que tanto para bolhas pequenas quanto para as maiores, a trajetória é muito próxima da retilínea.

\section{1 .4}

\section{Influência da tensão limite de escoamento nos resultados}

Com a finalidade de analisar qualitativamente o comportamento do escoamento da bolha de gás foi plotado um gráfico de $\mathrm{Re} x \mathrm{Y}$, este último sendo um parâmetro adimensional dado pela razão entre a tensão limite de escoamento e a tensão devido ao empuxo, conforme definido na Equação (2-1).

A bolha só irá se movimentar se $\mathrm{Y}$ for menor do que um valor crítico, ponto 


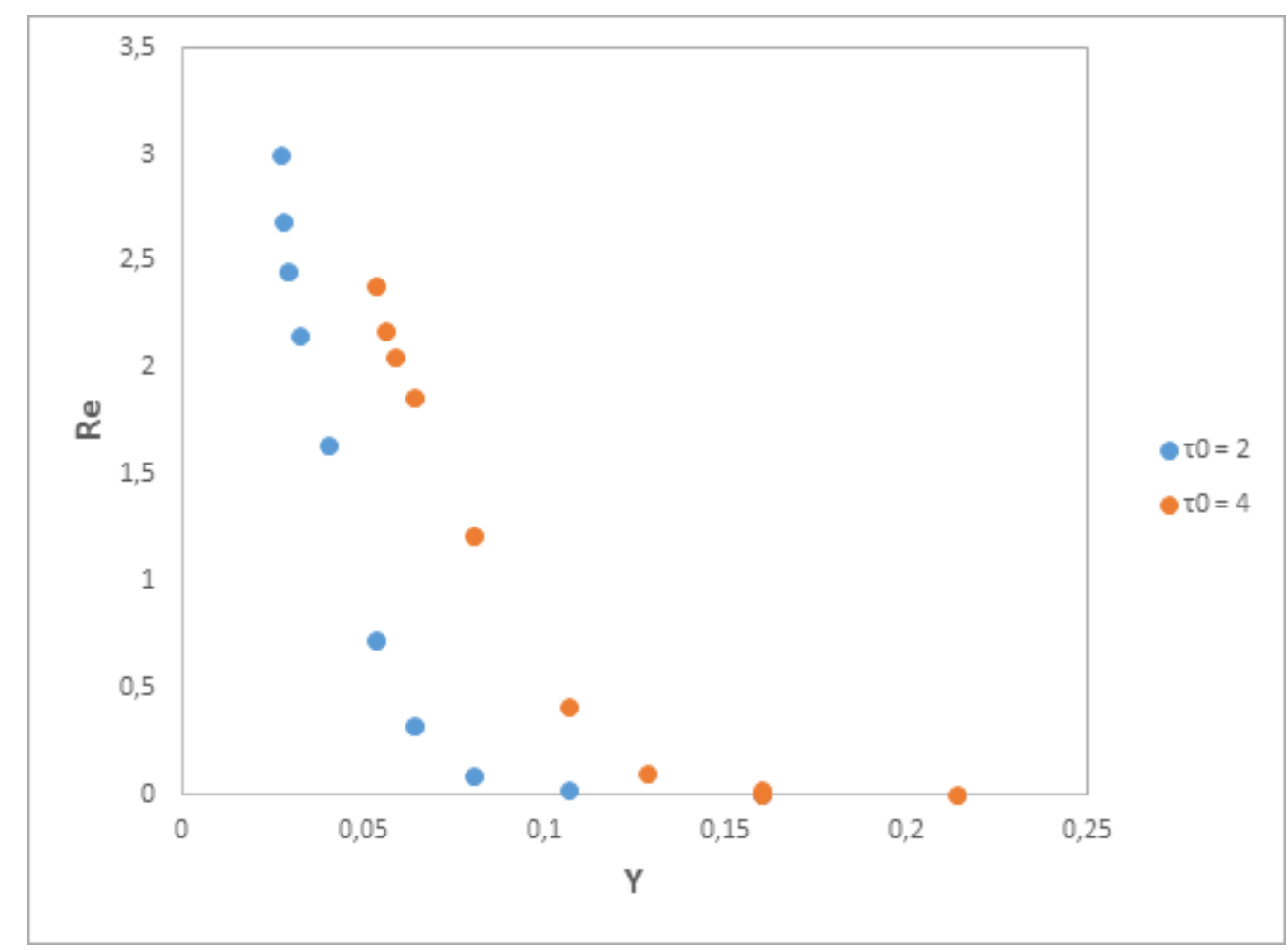

Figura 5.8: Número de Reynolds generalizado versus Y

em que a força de empuxo supera as forças devido a tensão limite de escoamento. Através do gráfico da Figura 5.8 pode-se observar diferentes valores para o Y crítico entre as duas curvas traçadas, sendo o valor encontrado para $\tau_{0}=2$ inferior ao encontrado para $\tau_{0}=4$, uma vez que ao aumentar o valor da tensão limite de escoamento se torna mais difícil de a bolha vence-la e começar a escoar.

\subsection{5}

\section{Análise do coeficiente de arraste}

O coeficiente de arraste foi estimado fazendo uso da equação (3-41), apresentada anteriormente, sendo a tensão cisalhante calculada pelo produto da viscosidade pela magnitude da taxa de deformação na superfície da bolha, este valor foi obtido através do Fluent na interface (fração volumétrica igual a 0,5 ) entre a bolha e o fluido.

Com a finalidade de validar os valores calculados para o coeficiente de atrito foi feita uma comparação com os resultados obtidos pelo modelo de du Plessis e Ansley (2006). Este modelo possui uma flexibilidade de aplicação permitindo ser usado para diferentes tipos de fluido como Herschel-Bulkley, Bingham, Power-Law e Newtoniano.

Este modelo foi feito baseado em equações para esfera sólida escoando em fluido viscoplástico porém foi determinado que também pode ser aplicada para 
bolhas de gás ao adicionar um fator de correção da superfície da partícula (x) que corrige o efeito de recirculação de gás presente nas bolhas.

O coeficiente de arraste do modelo de du Plessis e Ansley é dado por:

$$
C d=\frac{24}{R e_{g}} x(1+y B i)
$$

Sendo $R e_{g}$ calculado por:

$$
R e_{g}=\frac{\rho v^{2-n} d^{n}}{k}
$$

Onde $R e_{g}$ representa o número de Reynolds generalizado, $\rho$ a massa específica do fluido, $v$ a velocidade termina da bolha, $d$ o diâmetro da bolha, $n$ o índice de comportamento do fluido, $k$ o índice de consistência, $x$ o fator de correção de superfície e $y$ o fator reológico que transforma de Newtoniano para não-Newtoniano.

No gráfico da Figura 5.9 foi plotada a curva $C_{d}$ versus $\operatorname{Re}_{g}$ considerando os resultados ao utilizar a Equação (3-41) e também o modelo de du Plessis e Ansley apresentado acima.

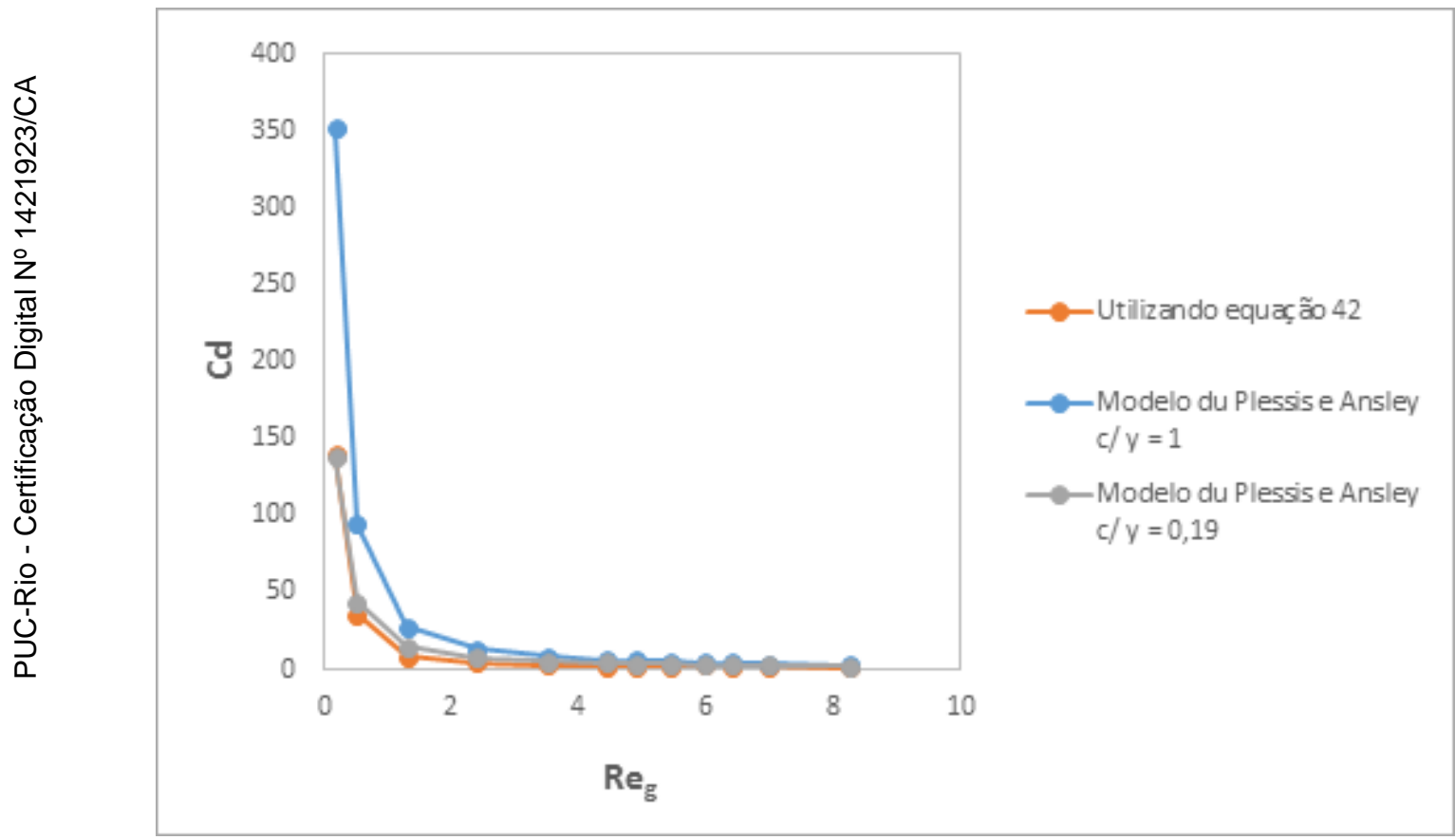

Figura 5.9: $\mathrm{C}_{d}$ versus $\mathrm{Re}_{g}$

O valor do fator y do modelo de du Plessis e Ansley foi variado, sendo o valor igual a 1 considerando que o fluido se comporta como Newtoniano e alterando este valor até que se aproximasse da curva onde $\mathrm{Cd}$ havia sido calculado utilizando a Equação (3-41), obtendo um valor de y igual a 0,19. Logo, o Cd calculado no presente trabalho pode ser validado utilizando a equação do modelo de du Plessis e Ansley considerando um fator y igual a 0,19 , que transforma o comportamento de um fluido Newtoniano para o fluido Herschel-Bulkley do estudo. 


\section{2}

\section{Análise do escomento com mais de uma bolha na vertical}

Nesta seção serão analisados os resultados das simulações realizadas com mais de uma bolha. A Tabela 5.3 resume os casos simulados, variando-se o número de bolhas escoando no fluido viscoplástico e o espaçamento entre as mesmas (h).

\begin{tabular}{|c|c|c|c|c|c|c|}
\hline Caso & $\tau_{0}(\mathrm{~Pa})$ & Número de bolhas & \begin{tabular}{|c} 
Raio da bolha \\
$(\mathrm{m})$
\end{tabular} & $d / L$ & \begin{tabular}{|c|} 
Distância entre as bolhas \\
$(\mathrm{m})$
\end{tabular} & $h / L$ \\
\hline$A$ & \multirow{6}{*}{2} & \multirow{4}{*}{2} & \multirow{8}{*}{0,002} & \multirow{8}{*}{0,12} & 0,01 & 0,3 \\
\hline$B$ & & & & & 0,02 & 0,6 \\
\hline $\mathrm{C}$ & & & & & 0,03 & 0,9 \\
\hline $\mathrm{D}$ & & & & & 0,04 & 1,2 \\
\hline $\mathrm{E}$ & & 3 & & & 0,01 & 0,3 \\
\hline $\mathrm{F}$ & & 5 & & & 0,01 & 0,3 \\
\hline G & \multirow{2}{*}{4} & 2 & & & 0,02 & 0,6 \\
\hline $\mathrm{H}$ & & 3 & & & 0,01 & 0,3 \\
\hline
\end{tabular}

Tabela 5.3: Simulações realizadas com mais de uma bolha

Primeiramente foi realizada uma comparação entre os resultados dos casos $\mathrm{A}, \mathrm{B}, \mathrm{C}$ e D plotando-se um gráfico do número de Reynolds versus $\mathrm{x} / \mathrm{H}$ sendo $\mathrm{x}$ a posição da bolha e $\mathrm{H}$ o comprimento da placa para diferentes instantes de tempo. Posteriormente foi feita uma comparação com resultado do deslocamento de apenas uma bolha.

A Figura 5.10 representa o deslocamento de 2 bolhas, com espaçamento inicial na vertical de $0,01 \mathrm{~m}$ entre elas, em fluido viscoplástico com $\tau_{0}=2$. Foram verificadas as velocidades de cada bolha em diferentes instantes de tempo (de T1 a T6).

Analisando o gráfico da Figura 5.10 pode-se constatar que a segunda bolha se desloca com uma velocidade superior a da primeira até o momento em que se encontram, em aproximadamente $0,56 \mathrm{~s}$ onde ocorre um pico na velocidade. A partir de então forma-se uma bolha única de tamanho maior que se desloca com uma velocidade bem superior a da bolha sozinha. A bolha que foi formada se desloca com um número de Reynolds aproximadamente constante de 0,4 .

A Figura 5.11 representa o deslocamento de 2 bolhas, agora com espaçamento de $0,02 \mathrm{~m}$ entre elas, em fluido viscoplástico com $\tau_{0}=2$. Foram verificadas as velocidades de cada bolha em diferentes instantes de tempo (de T1 a T8).

Analisando o gráfico da Figura 5.11 pode-se também observar que a segunda bolha se desloca com uma velocidade maior do que a primeira porém demora um pouco mais para que as bolhas se juntem, a aproximadamente 2,3 s após o início do deslocamento. Também foi observado um pico na velocidade quando as bolhas se 


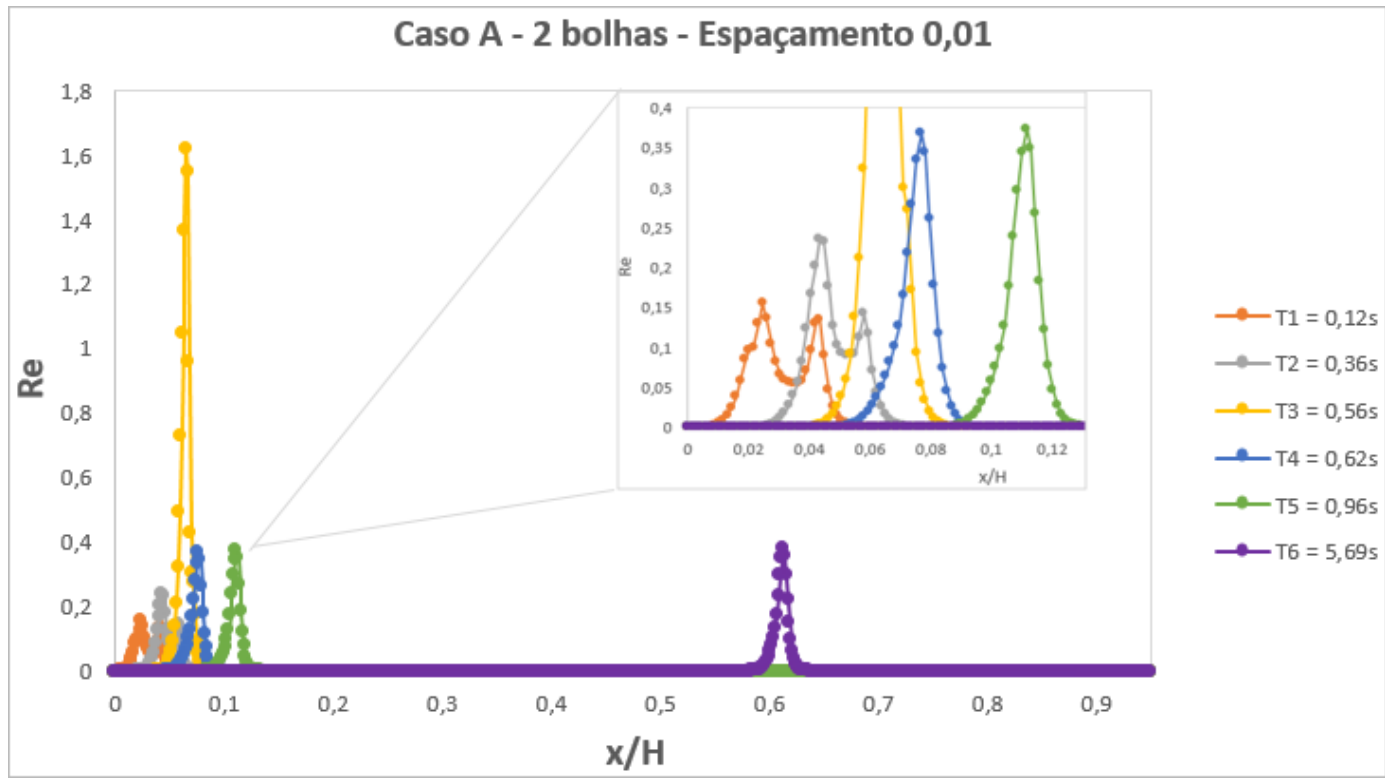

Figura 5.10: Gráfico Re vs x/H para escoamento de 2 bolhas com espaçamento de $0,01 \mathrm{~m}$ e $\tau_{0}=2$

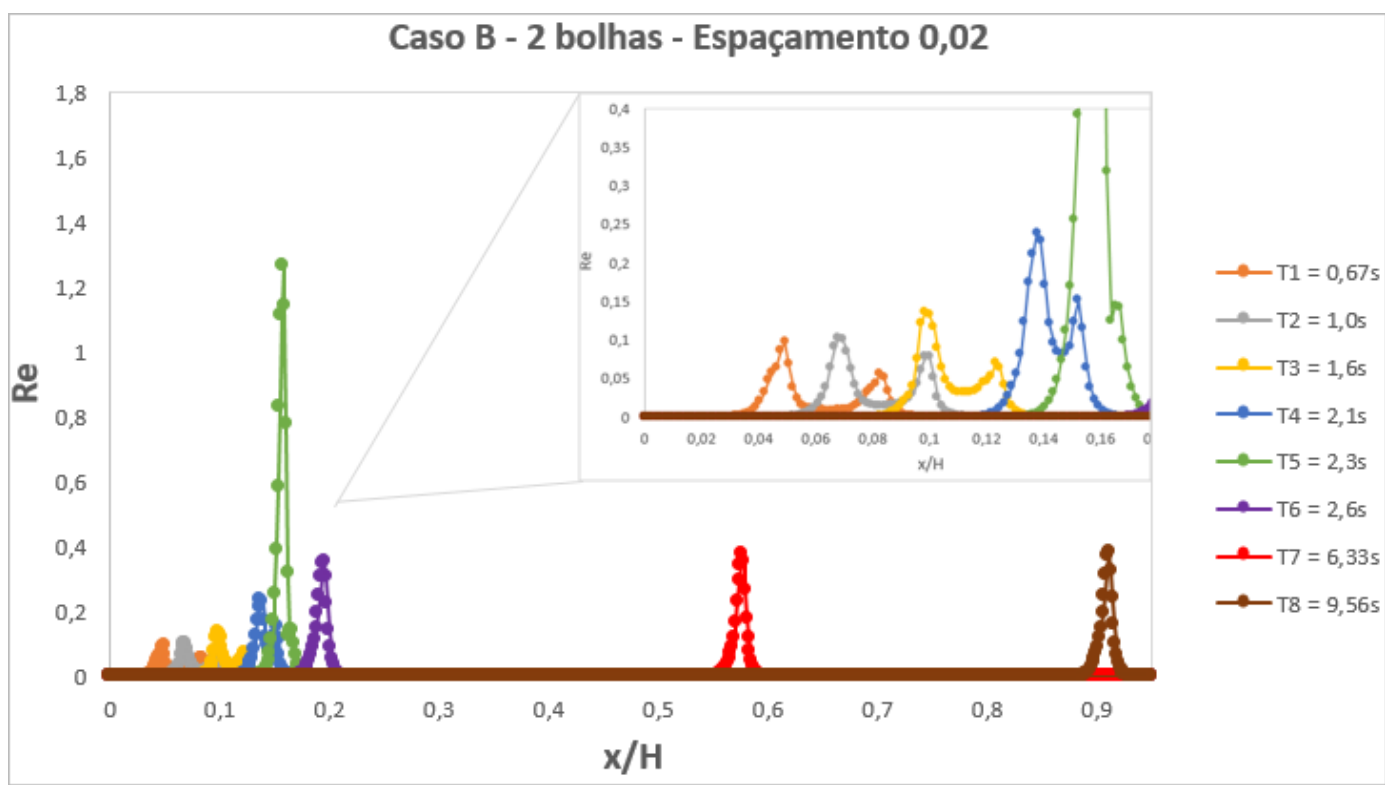

Figura 5.11: Gráfico Re vs x/H para escoamento de 2 bolhas com espaçamento de $0,02 \mathrm{~m}$ e $\tau_{0}=2$

juntaram e uma velocidade similar aproximadamente constante após a junção das bolhas.

O mesmo comportamento pode ser observado no gráfico da Figura 5.12, onde o espaçamento entre as bolhas foi de $0,03 \mathrm{~m}$, sendo o momento em que as bolhas se juntam mais tardio em relação aos casos A e B.

Pode-se notar que inicialmente a diferença de velocidade entre a primeira e 


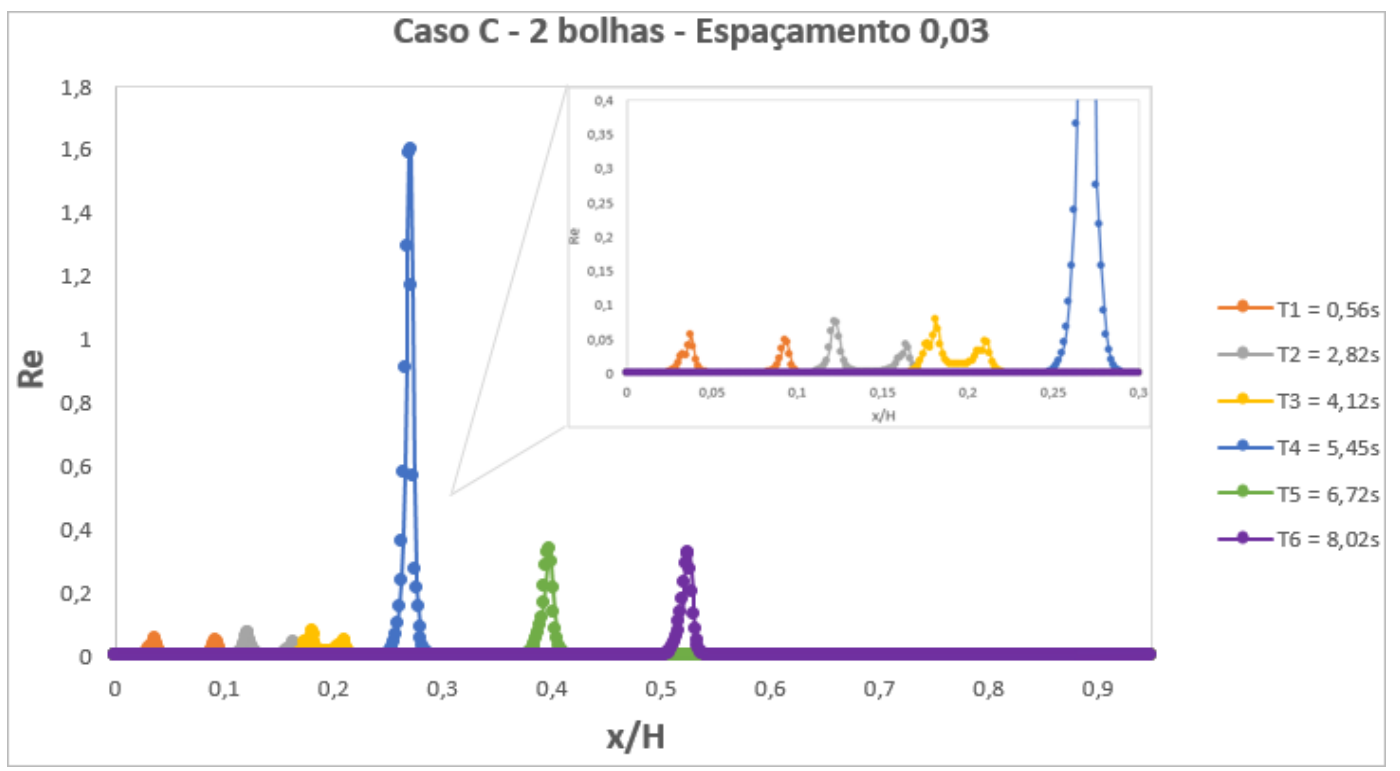

Figura 5.12: Gráfico Re vs x/H para escoamento de 2 bolhas com espaçamento de $0,03 \mathrm{~m}$ e $\tau_{0}=2$

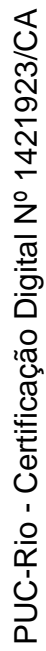

segunda bolha neste caso não é tão grande. Isto se deve ao fato de que como elas não estão tão próximas, a influência entre seus campos de velocidade e de taxa de deformação não é tão grande, o que pode ser verificado melhor na Figura 5.13.

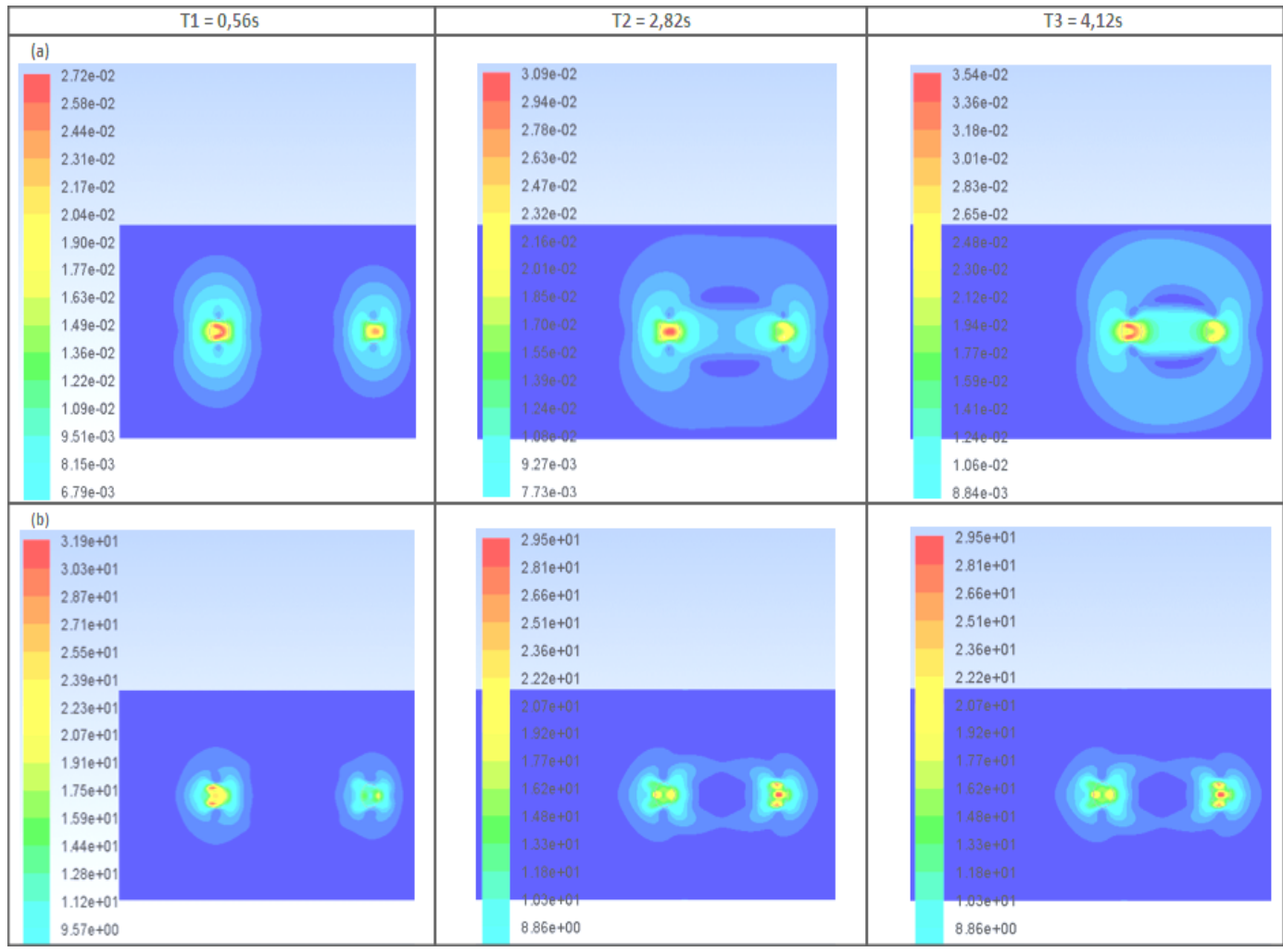

Figura 5.13: Campos (a) velocidade e (b) taxa de deformação em diferentes instantes de tempo para o caso $\mathrm{C}$ 
No primeiro instante $(\mathrm{t}=0,56 \mathrm{~s})$ os campos não interferem um no outro. A medida em que o escoamento segue as duas bolhas se aproximam e a velocidade da segunda bolha é alterada devido a duas causas: primeiro pelo fato de ter influência da primeira bolha no campo de velocidade, levando a uma diferença na força de arraste e segundo pelo fato de que a taxa de deformação também será alterada o que acarretará em viscosidades diferentes pois o fluido é não-newtoniano. O fluido estará menos deformado a frente da primeira bolha e consequentemente um nível de viscosidade mais elevado é encontrado. Já na região entre as bolhas as taxas de deformação serão maiores pois terá uma deformação influenciada pelo movimento tanto da primeira bolha quanto da segunda e consequentemente nesta região o nível de viscosidade será menor facilitando o escoamento da segunda bolha, tornandoa mais acelerada. Acredita-se também que seja possível que uma parcela desta diferença entre as velocidades das bolhas seja devido a aproximação que é feita na criação das bolhas esféricas, uma vez que os elementos da malha são retangulares, o formato inicial das duas bolhas não é exatamente igual. Ao inserir duas bolhas no fluido, em posições diferentes, as mesmas adquirem formatos um pouco distintos um do outro. Talvez para mitigar este problema seja necessário refinar mais ainda a malha e utilizar elementos mais adequados porém tornaria o custo computacional muito alto e o ganho pode não justificar.

A medida em que as bolhas se tornam mais próximas, os campos interferem mais significativamente um no outro, levando a um acréscimo ainda maior na velocidade da segunda bolha até o momento em que as bolhas se encontram $(\mathrm{t}=$ $5,45 \mathrm{~s})$.

Além do fato de os campos interferirem um no outro modificando a velocidade das bolhas acredita-se também que a passagem da primeira bolha forme uma espécie de canal para trás através do qual a segunda bolha irá propagar, o que altera seu formato e velocidade. Estas mesmas alterações na velocidade da segunda bolha foram observadas nos estudos realizados por Dubash et al (2007) e Piau et al (2012).

A Figura 5.14 representa o deslocamento das duas bolhas, neste caso com espaçamento de $0,04 \mathrm{~m}$ entre elas. Foram verificadas as velocidades de cada bolha em diferentes instantes de tempo (de T1 a T6).

No caso representado na Figura 5.14 o espaçamento entre as bolhas é grande o suficiente para que as duas bolhas não se encontrem permanecendo com uma velocidade aproximadamente constante ao longo do escoamento. Acredita-se que a mesma influência devido a aproximação no formato ao criar as bolhas, conforme visto anteriormente, também esteja ocorrendo neste caso, o que justificaria a pequena diferença de velocidade entre as duas bolhas.

Foi também plotado um gráfico para representar o escoamento de apenas uma bolha de raio 0,002 m para servir de comparação com o caso $\mathrm{D}$, uma vez que, como 


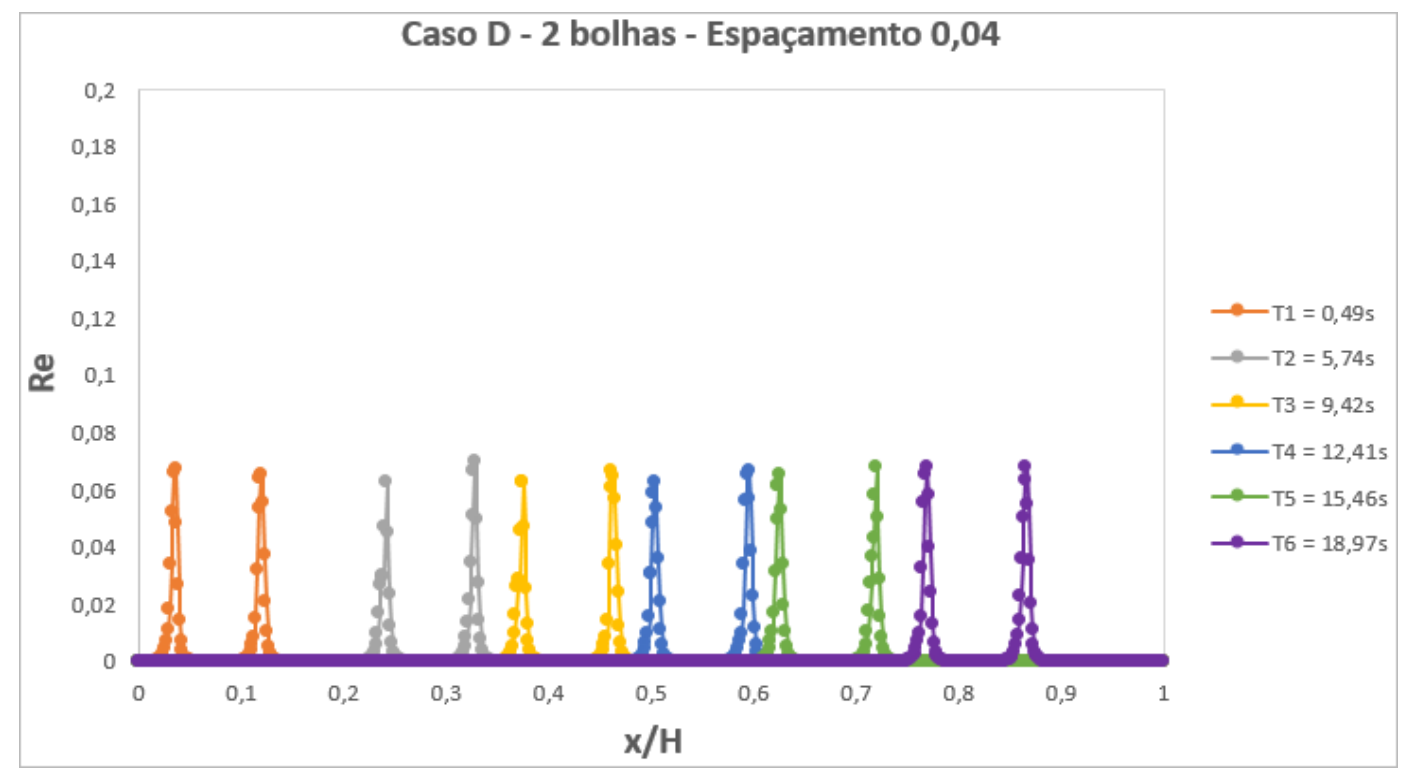

Figura 5.14: Gráfico Re vs x/H para escoamento de 2 bolhas com espaçamento de $0,04 \mathrm{~m}$ e $\tau_{0}=2$

as bolhas não se encontram e seus campos não influenciam um no outro, acredita-se que as mesmas escoando separadamente deveriam ter um comportamento similar ao de uma bolha escoando sozinha.

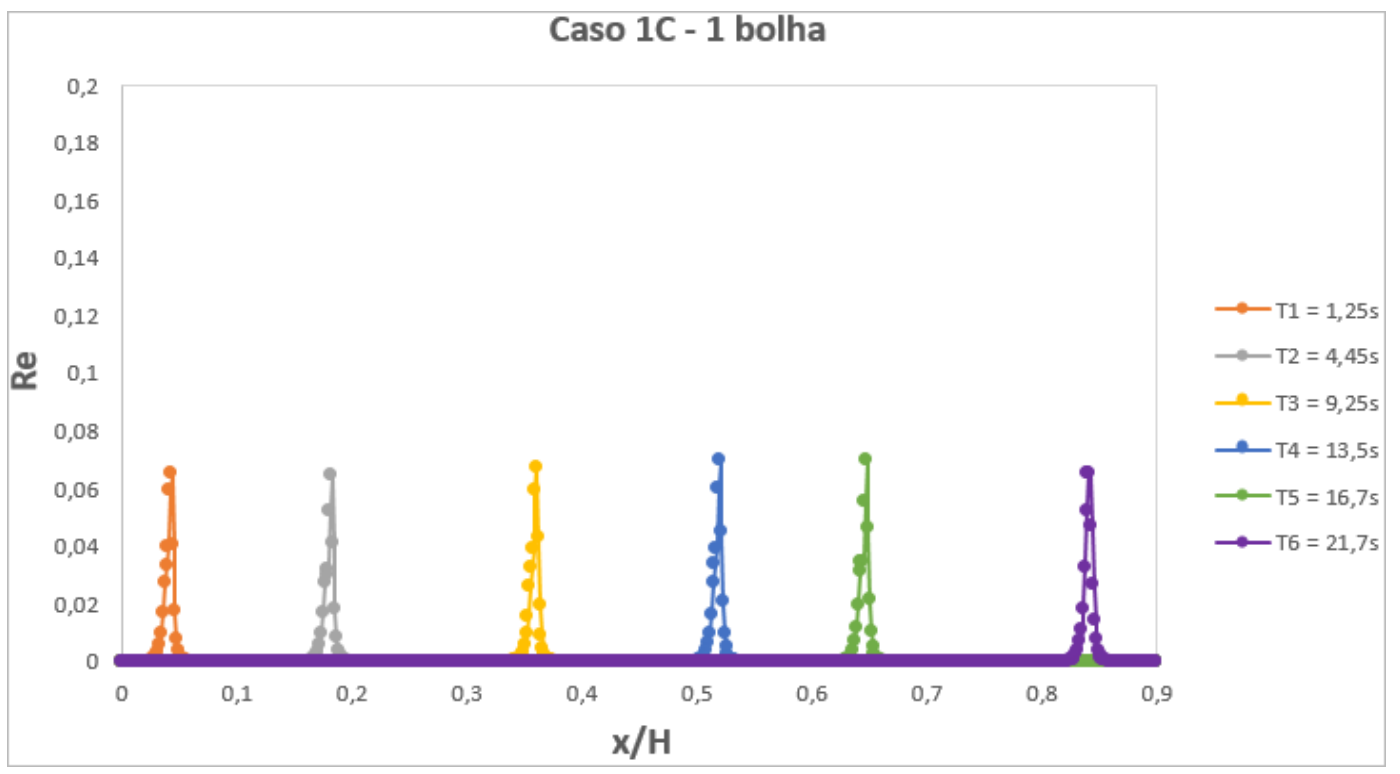

Figura 5.15: Gráfico Re vs x/H para escoamento de 1 bolha com raio de 0,002 m e $\tau_{0}=2$

Levando em consideração a interferência da aproximação feita ao inserir as bolhas esféricas na simulação pode-se considerar que no caso em que as bolhas não se juntam as mesmas possuem um comportamento bastante similar ao comportamento do escoamento de uma bolha sozinha. 
Foi realizada uma simulação com 2 bolhas considerando o $\tau_{0}=4$ a fim de comparar a diferença no comportamento ao aumentar a tensão limite de escoamento. Qualitativamente o resultado foi muito similar e quantitavamente o comportamento foi conforme o esperado, como pode ser observado na Figura 5.16.

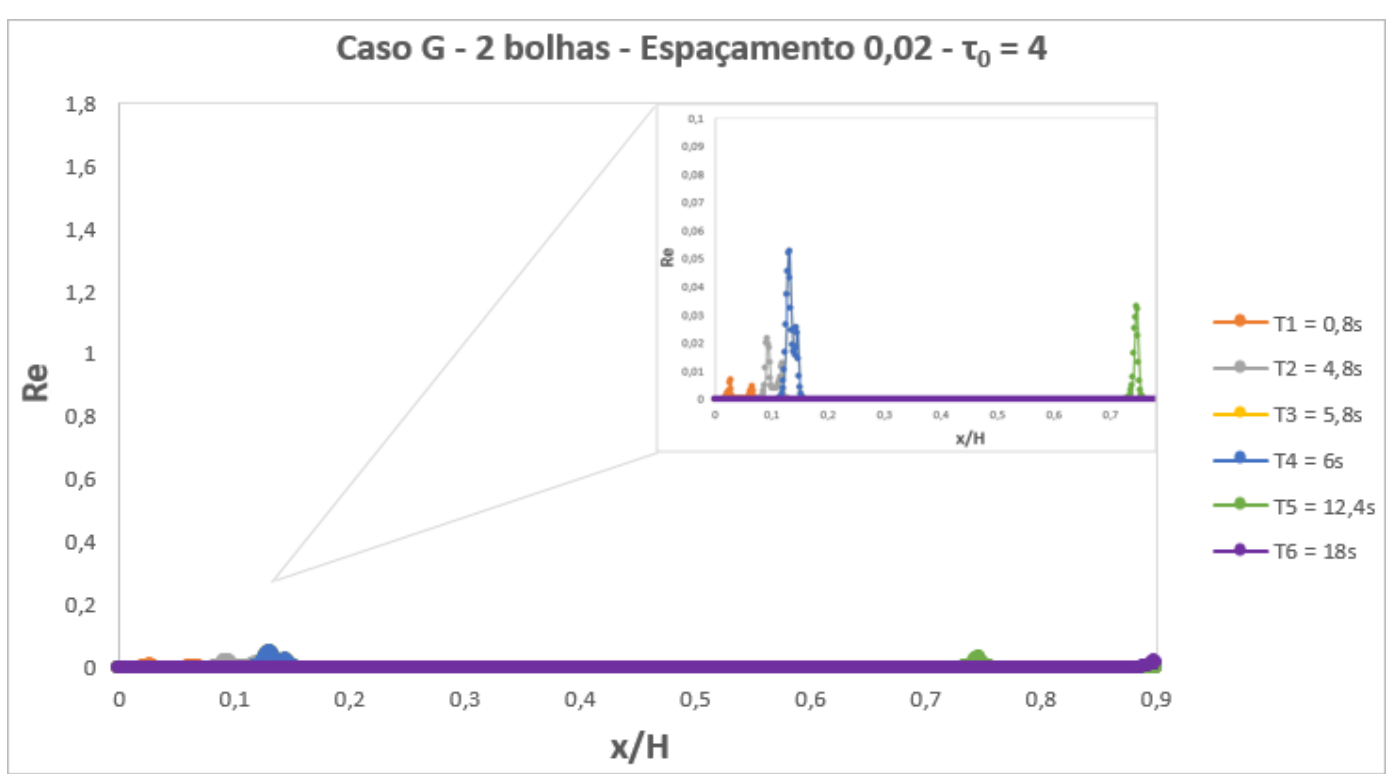

Figura 5.16: Gráfico Re vs x/H para escoamento de 2 bolhas com espaçamento de $0,02 \mathrm{~m} \mathrm{e} \tau_{0}=4$

Comparando o caso B com o caso $\mathrm{G}$, em ambos foi simulado o escoamento de 2 bolhas com raio igual a $0,002 \mathrm{~m}$ e espaçamento entre elas de 0,02 $\mathrm{m}$ com a diferença de que no caso $\mathrm{B}$ o fluido possui tensão limite de escoamento igual a $2 \mathrm{~Pa}$ e no caso $\mathrm{G}$ tensão limite de escoamento igual a $4 \mathrm{~Pa}$. Como era de se esperar, no caso $\mathrm{G}$ as bolhas tiveram mais dificuldade em se deslocar como pode ser observado no gráfico da Figura 5.16. As bolhas se deslocam com uma velocidade muito inferior se comparado ao caso B, também ocorre o pico de velocidade quando as bolhas se encontram e após este momento a bolha que se formou escoa com uma velocidade aproximadamente constante. O comportamento do escoamento ocorreu conforme esperado visto que a bolha tem mais dificuldade de escoar em fluido com tensão limite de escoamento maior.

Foi também realizada uma simulação considerando o escoamento de 3 bolhas de gás no fluido. A Figura 5.17 representa o escoamento em fluido com limite de escoamento igual a $2 \mathrm{~Pa}$. Este caso também foi simulado para escoamento em fluido de limite de escoamento igual a 4 Pa porém como o resultado qualitativo foi o mesmo, só será mostrado aqui o resultado do caso E.

Observa-se que no início do escoamento a última bolha e a bolha do meio escoam com velocidades similares, já a primeira bolha escoa com uma velocidade inferior. Acredita-se que isto se deva ao mesmo fato comentado anteriormente 


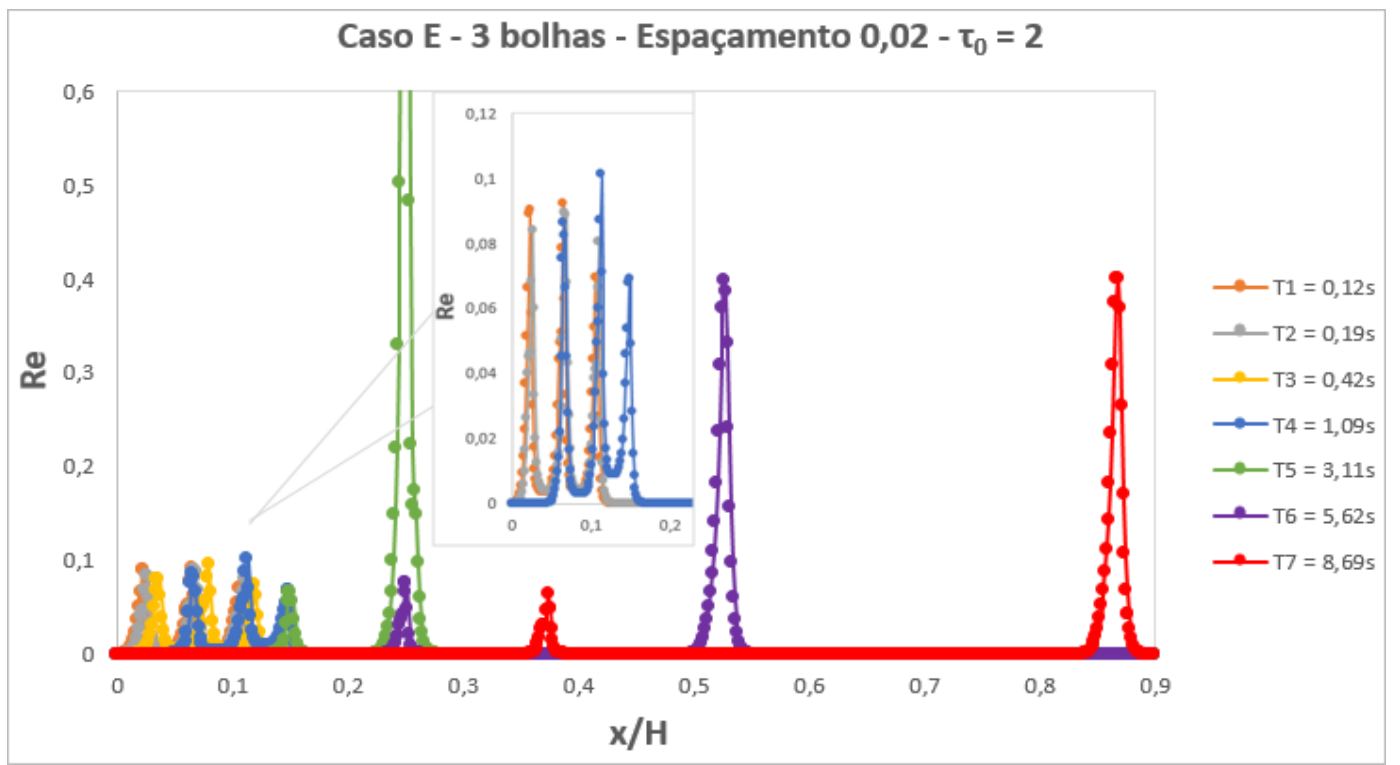

Figura 5.17: Gráfico Re vs x/H para escoamento de 3 bolhas com espaçamento de $0,02 \mathrm{~m} \mathrm{e} \tau_{0}=2$

\begin{tabular}{|c|c|c|}
\hline $\mathrm{T} 1=0,12 \mathrm{~s}$ & $\mathrm{~T} 2=0,19 \mathrm{~s}$ & $\mathrm{~T} 3=0,42 \mathrm{~s}$ \\
\hline $347 \mathrm{e}-02$ & $3.426-02$ & $3.546-02$ \\
\hline $3.300-02$ & $325 \mathrm{e}-02$ & $3,370.02$ \\
\hline $3.136 \cdot-02$ & $3080 \cdot 02$ & $3.190 \cdot 02$ \\
\hline $2956-02$ & $2900 \cdot .02$ & 3.016 .02 \\
\hline $2.78 \cdot .02$ & 2.73e-02 & $2.83 \mathrm{e}-02$ \\
\hline $2.61 \mathrm{e}-02$ & $2.56 \mathrm{e}-02$ & $2.66 \mathrm{e}-02$ \\
\hline $243 \mathrm{e}-02$ & $2.390 \cdot .22$ & $248 \mathrm{e}$ \\
\hline $2266-02$ & $2222-02$ & $2.300-$ \\
\hline $\begin{array}{l}2.088-02 \\
1.910-02\end{array}$ & $\begin{array}{l}2.056-02 \\
1.880-02\end{array}$ & $\begin{array}{l}2.136-9 \\
1.96 \mathrm{e}\end{array}$ \\
\hline $1.74 \mathrm{e}-02$ & $1.716-02$ & 1.77e. \\
\hline $1.56 \mathrm{e}-02$ & $1.54 \mathrm{e}-02$ & \\
\hline $1,39 \mathrm{e}-02$ & 1.370 .02 & $1.42 \mathrm{e}$ \\
\hline $1222-02$ & $1200 \cdot .2$ & $124 \mathrm{e}-02$ \\
\hline $1.04 \mathrm{e}-02$ & $1038 \cdot 02$ & $1.066-02$ \\
\hline $\mathrm{T} 1=1,09 \mathrm{~s}$ & $\mathrm{~T} 2=3,11 \mathrm{~s}$ & \\
\hline $3.67 \mathrm{e}-02$ & $1.62 \mathrm{e}-01$ & \\
\hline $\begin{array}{l}3.486-02 \\
3.30-02\end{array}$ & $\begin{array}{l}1.546-01 \\
146-01\end{array}$ & \\
\hline $\begin{array}{l}3.301-02 \\
3.128-02\end{array}$ & $\begin{array}{l}1.468-01 \\
1.380-01\end{array}$ & \\
\hline $2936-02$ & $1.300-01$ & \\
\hline $2.756-02$ & 1.220 .01 & \\
\hline $128 \mathrm{e} \cdot 02$ & $5.688-02$ & \\
\hline $1.100-02$ & $4.877-02$ & \\
\hline
\end{tabular}

Figura 5.18: Campo de velocidade em diferentes instantes do escoamento do caso $\mathrm{E}$

ocorrido com a primeira bolha no escoamento de apenas duas bolhas, como o fluido está menos deformado a frente da primeira bolha, consequentemente um nível de viscosidade mais elevado é encontrado, dificultando assim o escoamento da mesma. Em um segundo momento $(\mathrm{t}=0,19 \mathrm{~s})$ a bolha do meio passa a escoar mais rápido, se 


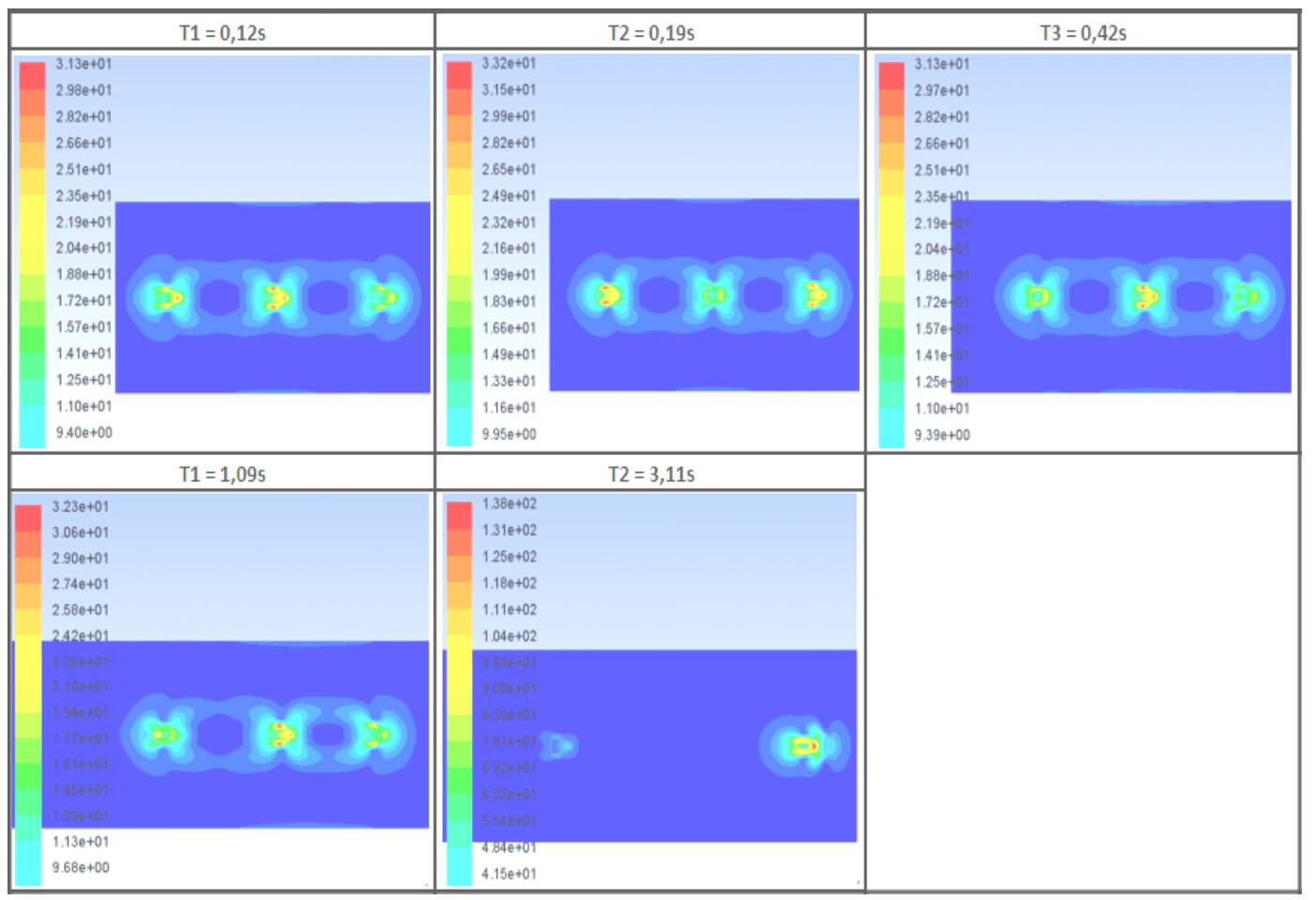

Figura 5.19: Campo taxa de deformação em diferentes instantes do escoamento do caso $\mathrm{E}$

aproximando da primeira bolha nos momentos subsequentes até que as duas bolhas se unem $(\mathrm{t}=3,11 \mathrm{~s})$, onde é possível observar um pico na velocidade, formando uma bolha de tamanho maior. Observando o campo taxa de deformação pode-se constatar que o campo ao redor da bolha do meio é maior, facilitando o escoamento da mesma pois torna os níveis de viscosidade em torno da mesma menores e por este motivo ela passa a escoar mais rapidamente até que se encontra com a primeira bolha. Nos instantes posteriores a bolha formada, de tamanho maior se distancia da terceira bolha pois sua velocidade é muito maior e a velocidade da terceira bolha diminui uma vez que o campo de velocidade da bolha maior já não interfere mais. Os campos de velocidade e taxa de deformação ao longo do tempo, até o momento em que as bolhas se juntam pode ser verificado nas Figuras 5.18 e 5.19.

\section{3}

\section{Análise do escomento com mais de uma bolha na horizontal}

Além de analisar bolhas escoando na vertical, também foi avaliado o escoamento de bolhas escoando na horizontal. Foram realizadas três simulações considerando esta disposição das bolhas, variando a distância horizontal entre elas $\left(h^{*}\right)$, conforme a Tabela 5.4 .

A Figura 5.20 mostra a trajetória de ascenção do par de bolhas de $2 \mathrm{~mm}$ de raio considerando os três diferentes intervalos iniciais entre as bolhas. 


\begin{tabular}{|c|c|c|c|c|c|c|}
\hline Caso & $\tau_{0}(\mathrm{~Pa})$ & Número de bolhas & $\begin{array}{c}\text { Raio da } \\
\text { bolha } \\
(\mathrm{mm})\end{array}$ & $d / L$ & \begin{tabular}{|c} 
Distância \\
entre as \\
bolhas \\
(mm) \\
\end{tabular} & $h^{*} / L$ \\
\hline $\mathrm{H} 1$ & \multirow{3}{*}{2} & \multirow{3}{*}{2} & \multirow{3}{*}{2} & \multirow{3}{*}{0,12} & 3 & 0,09 \\
\hline $\mathrm{H} 2$ & & & & & 7 & 0,21 \\
\hline H3 & & & & & 11 & 0,33 \\
\hline
\end{tabular}

Tabela 5.4: Simulações realizadas com mais de uma bolha escoando na horizontal

É possível observar mudanças no formato e trajetória das bolhas. A trajetória percorrida pelas bolhas é assimétrica ao longo de uma linha perpendicular no centro no eixo vertical. No caso em que a distância inicial entre as bolhas é igual a $3 \mathrm{~mm}$ (Figura 5.20(a)) percebe-se que no início do escoamento o formato da bolha se move no sentido anti-horário até se manter em uma posição constante a partir do tempo igual a 5,1 s. Também pode-se notar que as bolhas vão se distanciando entre si, até o mesmo momento de 5,1 s. Em relação ao par de bolhas com distância inicial entre elas de $7 \mathrm{~mm}$ (Figura 5.20(b)) é possível observar que as bolhas também se distanciam porém muito pouco, sendo quase imperceptível.

Este distanciamento entre as bolhas também foi observado no trabalho realizado por Tariqul Islam et al (2015). Acredita-se que este comportamento se deve a força repulsiva entre o par de bolhas como resultado de uma grande quantidade de vórtices gerados entre as bolhas. Esta repulsão é mais forte quando as bolhas estão mais próximas entre si e esta força vai se tornando insignificante a medida em que esta distância inicial entre as bolhas aumenta.

Ao analisar o comportamento das bolhas no caso em que a distância inicial entre elas é igual a $11 \mathrm{~mm}$ (Figura 5.20(c)) nota-se um efeito contrário, as bolhas se aproximam até uma distância muito próxima as obtidas nas simulações dos outros casos, podendo-se concluir que neste caso não há mais forças repulsivas e por este motivo as bolhas se aproximam até uma distância em que esta força torna-se significante. Acredita-se que esta aproximação esteja ocorrendo devido ao campo taxa de deformação que gera uma velocidade na direção do centro fazendo com que as mesmas se aproximem porém ao mesmo tempo existe a força repulsiva que impede que as bolhas se aproximem mais do que um certo ponto. Foi suspeitado que a parede também poderia estar afetando, neste caso ajudando a causar esta aproximação porém foi realizada uma simulação considerando uma distância entre as placas maior e o mesmo comportamento foi observado. 

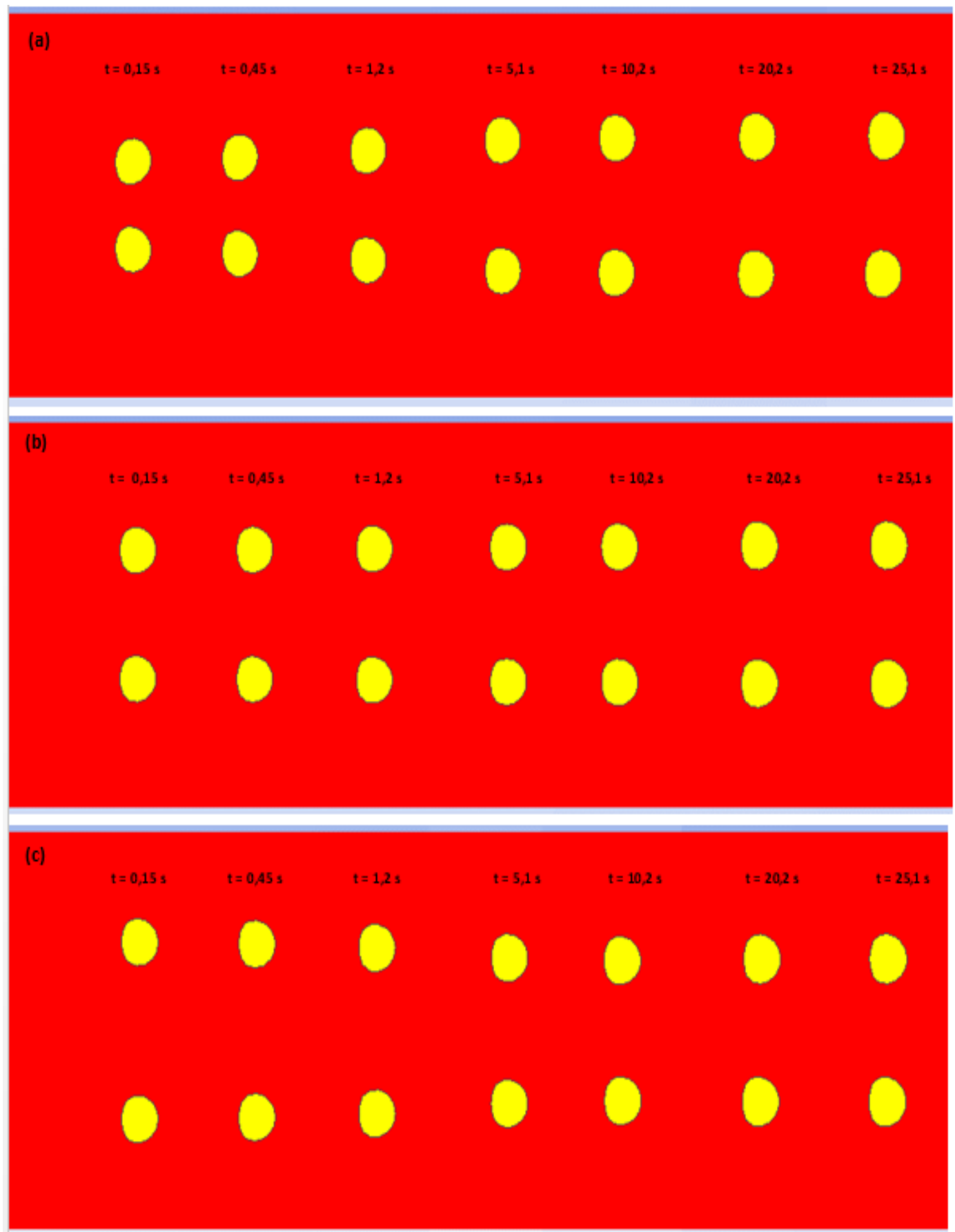

Figura 5.20: Trajetória de par de bolhas escoando paralelamente com diferentes distâncias iniciais entre elas: (a) $3 \mathrm{~mm}$ (b) $7 \mathrm{~mm}$ (c) $11 \mathrm{~mm}$

\section{4}

\section{Validação do modelo bidimensional}

A simulação realizada em domínio tridimensional, com a finalidade de validar o modelo bidimensional utilizado, foi feita considerando-se um raio de bolha igual a $3,35 \times 10^{-3} \mathrm{~m}$, este raio equivalente foi calculado a partir da equação 44 para um $R_{2 D}$ igual a $2 \times 10^{-3} \mathrm{~m}$. 
A velocidade média encontrada para o escoamento da bolha no domínio tridimensional para o tamanho de bolha mencionado anteriormente foi de $0,031 \mathrm{~m} / \mathrm{s}$ enquanto no domínio bidimensional, para o raio equivalente, foi de $0,034 \mathrm{~m} / \mathrm{s}$, o que reflete uma diferença de $10 \%$ entre as velocidades nos dois domínios simulados. 


\section{6 \\ Conclusão e recomendações}

\section{1 \\ Conclusões}

No presente trabalho foi analisado, através de simulações numéricas, o comportamento do movimento ascendente de bolhas de ar em fluido viscoplástico. Alguns parâmetros foram variados e suas influências no escoamento foram averiguadas.

Foi verificado que o custo computacional para realizar estas simulações em domínio tridimensional é muito alto, deste modo para que fosse possível realizar o estudo em tempo hábil, foi utilizada uma abordagem bidimensional, aproximando o problema por placas paralelas. Foi realizada uma simulação com geometria tridimensional para validar a consideração feita e o resultado foi satisfatório. Foi observada uma diferença na velocidade da bolha de $10 \%$ entre as abordagens, que foi considerada satisfatória.

A respeito da variação da tensão limite de escoamento do fluido, foram analisados fluidos com $\tau_{0}$ igual a 2 e $4 \mathrm{~Pa}$ e foi possível observar que com o aumento deste parâmetro a velocidade atingida pela bolha reduz. Isto acontece pois ao aumentar o valor deste parâmetro, a força de arraste aumenta causando assim uma desaceleração da partícula gasosa.

Foi observado que ao aumentar o diâmetro da bolha, a sua velocidade terminal também aumenta e seu formado é modificado. Uma vez que a velocidade aumenta, o número de Reynolds também aumenta então é possível verificar que ao aumentar este parâmetro o formato da bolha se modifica, passando de uma forma esférica para um formato elipsoidal.

Os efeitos da parede foram também analisados e foi percebido que a mesma começa a influenciar na velocidade de ascenção de bolhas quando a razão d/L (sendo $\mathrm{L}$ a distância entre as placas) é superior a 0,24 , pois o tamanho da bolha aumenta a ponto dos campos taxa de deformação e de velocidade da bolha sofrerem interferência da parede.

Observou-se que bolhas muito pequenas não possuem força de empuxo suficiente para vencer a tensão limite de escoamento do fluido e que a partir de um valor de raio crítico é possível vencer essa tensão limite e a bolha começar a 
escoar.

Ao se calcular o coeficiente de atrito e traçar um gráfico de $\mathrm{Cd}$ versus $\mathrm{Re}$ foi possível verificar que a equação do método do modelo de du Plessis e Ansley correspondia bem aos dados calculados ao considerar um fator $y$ que transforma o fluido de Newtoniano para não-Newtoniano igual a 0,19.

Neste trabalho foram considerados parâmetros e valores correspondentes a uma pasta de cimento utilizada em aplicação de cimentação de poços de petróleo. Porém as simulações do presente estudo podem ser exploradas ampliando o campo de aplicação para diferentes setores da indústria, tais como alimentos e bebidas, químico, farmacêutico, civil, dentro outros e até mesmo petroleiro, ao considerar fluido de perfuração ao invés de pasta de cimento.

Foi possível verificar, no escoamento de mais de uma bolha posicionadas verticalmente entre si, que a distância entre elas irá impactar no comportamento do escoamento. Ao analisar bolhas de razão d/L (sendo $\mathrm{L}$ a distância entre as placas) igual a 0,12 verificou-se que somente a partir de uma distância entre bolhas acima de uma razão $\mathrm{h} / \mathrm{L}$ (sendo $\mathrm{h}$ a distância entre as bolhas) de 1,21 as mesmas se comportam igual a uma bolha escoando sozinha no fluido. Isto acontece devido a influência de dois fatores: (1) do campo de velocidade de uma bolha na outra, se estão muito próximas pode causar um aumento na velocidade da segunda bolha fazendo com que as mesmas se juntem, aumentem de tamanho e passe a escoar com uma velocidade maior e (2) campo taxa de deformação que será alterado e irá influenciar no nível de viscosidade do fluido ajudando também a acelerar a segunda bolha. Ao se considerar o escoamento de uma bolha de gás durante a cimentação de um poço de petróleo isto seria um fator importante a se observar pois rapidamente poderia se formar uma bolha de maior tamanho, após duas bolhas se juntarem, e consequentemente a velocidade aumentar sendo necessário agir mais rapidamente para evitar que um acidente ocorra.

Na configuração do par de bolhas dispostas horizontalmente é possível observar que existe um efeito repulsivo entre elas que aumenta ao diminuir a distância entre as bolhas. Isto se deve a uma redução nas propriedades viscoplásticas do fluido, o que leva a uma intensificação dos vórtices entre as bolhas causando um afastamento entre elas.

\section{2}

\section{Sugestões para trabalhos futuros}

Por uma questão de limitação de tempo, o único parâmetro reológico do fluido que foi analisado no presente estudo foi a tensão limite de escoamento, $\tau_{0}$. Seria interessante também avaliar o efeito do índice de consistência, k, e também do índice de comportamento do fluido, n, no escoamento da bolha de gás. Isto 
também vale para os casos simulados com mais de uma bolha dispostas na vertical e horizontal.

Seria também interessante analisar a influência da tensão interfacial entre os fluidos no escoamento da bolha.

Como foi observado que o formato da bolha modifica ao aumentar o seu tamanho, o ideal seria fazer os cálculos dos parâmetros adimensionais analisados utilizando um diâmetro equivalente da bolha, considerando esta deformação. Para isto seria necessário determinar uma equação para o cálculo deste diâmetro.

Com a finalidade de validar os resultados encontrados no presente estudo numérico seria ideal realizar um estudo experimental com um fluido com parâmetros bem próximos aos considerados aqui, se possível.

Um trabalho futuro muito importante seria melhorar a forma de projetar as pastas de cimento usadas no campo, alterando suas propriedades reológicas, de modo a evitar a migração de gás. 


\section{Referências bibliográficas}

ABDU, A.; NACCACHE, M. F.; MENDES, P. R. S. Effect of Rheology on Well Plugging Process. IMECE 2012-8614, p. 3-4, 9 p, 2012.

ASLAN, J. F.; Aspectos de Segurança na Cimentação de Poços de Petróleo. São Paulo: Revista Petróleo e Energia, p. 4 - 14, 15 dez. 2015.

BARNES, H.A.; HUTON, J.F.; WALTERS, K. An introduction to rheology. Amsterdam: Elsevier Science, 1989, $199 \mathrm{p}$.

BERIS, A.N.; TSAMOPOULOS, J.A.; ARMSTRONG, R.C.; BROWN, R.A. Creeping flow of $\mathbf{s}$ sphere through a Bingham plastic. Fluid Mech, 158:219244, 1985.

BIRD, B., STEWART, W.E. e LIGHTFOOT, E.N., Fenômenos de Transporte, $2^{2}$ Ed. Rio de Janeiro: LTC, 2004.

BRACKBILL J.U.; KOTHE D.B.; ZEMACH C. A continuum method for modeling surface tension. Journal of computational physics, 100:335-354, 1992.

CANDELA, W. F. L. Modelo Matemático Simplificado para Migração de Bolhas de Gás em Fluido Viscoplastico. Dissertação de Mestrado, Pontifícia Universidade Católica do Rio de Janeiro, Rio de Janeiro, RJ, Brasil, 2013.

CHHABRA, R. P.; Bubble, Drops, and Particles in Non-Newtonian Fluids. Taylor \& Francis, 2007. (Boca Raton, FL).

CLIFT, R., GRACE, J.R. e WEBER, M.E. Bubbles, Drops and Particles. New York: Academic Press, Inc., 1978.

DIMAKOPOULOS, Y.; PAVLIDIS, N.; TSAMOPOULOS, J. Steady bubble rise in Herschel-Bulkley fluids and comparison of predictions via the Augmented Lagrangian Method with those via the Papanastasiou model. 
Journal of Non-Newtonian Fluid Mechanics, 200:34-51, 2013.

DUBASH, N. Bubble propagation through viscoplastic fluids. Tese de Doutorado, The University of British Columbia, Vancouver, Canada, 2003.

DUBASH, N.; FRIGAARD, I. Conditions for static bubbles in viscoplastic fluids. Physics of Fluids 16:4319-4330, 2004.

DUBASH, N.; FRIGAARD, I. Propagation and stopping o fair bubble in Carbopol solutions. Journal of Non-Newtonian Fluid Mechanics, 142:123-134, 2007.

FLUENT USER'S GUIDE, v. 15.2, Fluent Inc., New Hampshire, 2006.

FOX, R. W. e MCDONALD, A. T., Introduction to Fluid Mechanics, McGrawHill, 2001.

GEORG I. C.; REZENDE R. V. P.; MALISKA, C. R. Estudo numérico do escoamento ascendente de uma bolha de gás em um meio líquido. $1^{\circ}$ Encontro Brasileiro sobre Ebulição, Condensação e Escoamento Multifásico Líquido-Gás, 2008.

GONZALO, V.; AISKELY, B.; ALICIA, C.; INTEVEP, P. A methodology to evaluate the gas migration in cement slurries. Technical Report SPE94901, Society of Petroleum Engineers, 2005.

ISLAM, M. T.; GANESAN, P.; CHENG, J. A pair of bubbles'rising dynamics in a xanthan gum solution: a CFD study. RSC Adv., 5:7819-7831, 2015.

KULKARNI A. A.; JOSHI J. B. Bubble formation and bubble rise velocity in gas-liquid systems: A review. Industrial \& Engineering Chemistry Research, 44:5873-5931, 2005.

MAGNAUDET J.; EAMES I. The motion of high-Reynolds-number bubbles in inhomogeneous flows. Annu. Ver. Fluid Mech, 32:659-708, 2000.

MOUGIN N.; MAGNIN A.; PIAU J. The significant influence of internal stresses on the dynamics of bubbles in a yield stress fluid. Journal of Non-Newtonian Fluid Mechanics, 171-172:42-55, 2012. 
RAYMOND F.; ROSANT J. -M. A numerical and experimental study of the terminal velocity and shape of bubbles in viscous liquids. Chemical Engineering Science, 55:943-955, 2000.

SANTOS, O. L. A.; AZAR, J.J. A study on gas migration in stagnant non-newtonian fluids. Technical Report SPE39019, Society of Petroleum Engineers, 1997.

SIKORSKI, D.; TABUTEAU, H.; DE BRUYN, J. R. Motion and shape of bubbles rising through a yield-stress fluid. Journal of Non-Newtonian Fluid Mechanics, 159:10-16, 2009.

TRIPATHI M. K.; SAHU K. C.; KARAPETSAS G.; MATAR O. K. Bubble rise dynamics in a viscoplastic material. Journal of Non-Newtonian Fluid Mechanics, 222:217-226, 2015.

TSAMOPOULOS J.; DIMAKOPOULOS Y.; CHATZIDAI N.; KARAPETSAS G.; PAVLIDIS M. Steady bubble rise and deformation in Newtonian and viscoplastic fluids and conditions for bubble entrapment. Journal of Fluid Mechanics, 601:123-164, 2008. 